\title{
Oncomodulin (OCM) uniquely regulates calcium signaling in neonatal cochlear outer hair cells.
}

Kaitlin E. Murtha ${ }^{*}$, Yang Yang ${ }^{*}$, Federico Ceriani², Jing-Yi Jeng ${ }^{2}$, Leslie K. Climer ${ }^{1}$, Forrest Jones ${ }^{1}$, Jack Charles ${ }^{1}$, Sai K. Devana ${ }^{3}$, Aubrey J. Hornak $^{1}$, Walter Marcotti ${ }^{2,4}$, Dwayne D. Simmons ${ }^{1,2,3,5, \#}$

${ }^{*}$ These authors contributed equally to this work.

${ }^{1}$ Department of Biology, Baylor University, 101 Bagby Ave, Waco, TX

${ }^{2}$ School of Biosciences, University of Sheffield, S10 2TN Sheffield,

United Kingdom

${ }^{3}$ Department of Integrative Biology and Physiology, University of

California, Los Angeles, CA

${ }^{4}$ Sheffield Neuroscience Institute, University of Sheffield, Sheffield, S10

2TN, UK

${ }^{5}$ Department of Psychology and Neuroscience, Baylor University, Waco, TX

\#To whom correspondence should be addressed:

dwayne_simmons@baylor.edu

Keywords:

EF-hand calcium-binding protein $(\mathrm{CaBP})$

Calcium signaling

Outer Hair Cell (OHC)

Oncomodulin (OCM)

Parvalbumin

Auditory development

Postnatal cochlea 


\section{Abstract}

In cochlear outer hair cells (OHCs), a network of $\mathrm{Ca}^{2+}$ channels, pumps and $\mathrm{Ca}^{2+}$-binding proteins (CaBPs) regulates the localization, spread, and magnitude of free $\mathrm{Ca}^{2+}$ ions. During early postnatal development, OHCs express three prominent mobile EF-hand CaBPs: oncomodulin (OCM), $\alpha$ parvalbumin (APV) and sorcin. We have previously shown that deletion of $\mathrm{Ocm}\left(\mathrm{Ocm}^{-/-}\right)$gives rise to progressive cochlear dysfunction in young adult mice. Here, we show that changes in $\mathrm{Ca}^{2+}$ signaling begin early in postnatal development of $\mathrm{Ocm}^{-/}$mice. While mutant OHCs exhibit normal electrophysiological profiles compared to controls, their intracellular $\mathrm{Ca}^{2+}$ signaling is altered. The onset of OCM expression at postnatal day 3 (P3) causes a developmental change in $\mathrm{KCl}$-induced $\mathrm{Ca}^{2+}$ transients in $\mathrm{OHCs}$ and leads to slower $\mathrm{KCl}$-induced $\mathrm{Ca}^{2+}$ transients than those elicited in cells from $\mathrm{Ocm}^{-/-}$littermates. We compared OCM buffering kinetics with other CaBPs in animal models and cultured cells. In a double knockout of $\mathrm{Ocm}$ and $\mathrm{Apv}$ $\left(\mathrm{Ocm}^{-/} ; \mathrm{Apv}^{-/}\right)$, mutant $\mathrm{OHCs}$ show even faster $\mathrm{Ca}^{2+}$ kinetics, suggesting that APV may also contribute to early postnatal $\mathrm{Ca}^{2+}$ signaling. In transfected HEK293T cells, OCM slows $\mathrm{Ca}^{2+}$ kinetics more so than either APV or sorcin. We conclude that OCM controls the intracellular $\mathrm{Ca}^{2+}$ environment by lowering the amount of freely available $\left[\mathrm{Ca}^{2+}\right]_{\mathrm{i}}$ in $\mathrm{OHCs}$ and in transfected HEK293T cells. We propose that OCM plays an 


\section{Introduction}

Outer hair cells (OHCs) are unique motor-sensory cells responsible for cochlear amplification and give rise to the exquisite sensitivity and frequency selectivity of mammalian hearing. Mammalian OHCs use a variety of organelles and proteins to regulate $\mathrm{Ca}^{2+}$ signaling. In $\mathrm{OHCs}$, the influx of $\mathrm{Ca}^{2+}$ primarily comes through mechanoelectrical transduction (MET) channels located in the stereocilia and through voltage-gated $\mathrm{Ca}^{2+}$ channels localized at the basolateral membrane [1-3]. Calcium extrusion is accomplished via plasma membrane $\mathrm{Ca}^{2+}$-ATPase (PMCA2) pumps localized to $\mathrm{OHC}$ stereocilia $[4, \underline{5}]$. Within $\mathrm{OHCs}, \mathrm{Ca}^{2+}$ is stored in an elaborate network of subsurface cisternae, which functions as a modified endoplasmic reticulum, as well as in mitochondria and the nucleus []]. Additional key players controlling $\mathrm{OHC} \mathrm{Ca}^{2+}$ dynamics are the developmentally regulated EF-hand $\mathrm{Ca}^{2+}$ binding proteins (CaBPs) that serve as mobile buffers $[\underline{7}, \underline{8}]$. These components are all integral to the $\mathrm{Ca}^{2+}$ signaling network within $\mathrm{OHCs}$ and, prior to hearing onset, will undergo developmental changes important to the functional maturation of $\mathrm{OHCs}$ (Figure 1A).

A wide variety of EF-hand CaBPs have been developmentally characterized in the cochlea [8-10], but their role in $\mathrm{OHC}$ maturation remains obscure. Developmental expression patterns of two parvalbumin isoforms, $\alpha$-parvalbumin $(A p v)$ and $\beta$-parvalbumin/oncomodulin $(\mathrm{Ocm})$, are well documented in the organ of Corti [11-13]. At P0, APV protein expression is abundant and diffuse (Figure 1A) [12]. During OHC maturation, OCM protein expression increases dramatically, while APV expression is downregulated [12, 14, 15]. Recently, sorcin (Sri), a CaBP involved in maintaining ER $\mathrm{Ca}^{2+}$ homeostasis, was identified as a top celltype defining gene for OHCs, along with Slc26a5 (encoding the motor protein prestin) and $\operatorname{Ocm}[\underline{16}, \underline{17}]$. 
The most abundant CaBP in adult OHCs is OCM [12]. Following the onset of hearing in rodents, OCM localizes to the lateral membrane but is also abundant in the cytoplasm and nucleus (Figure 1A,B). Targeted deletion of $\mathrm{Ocm}$ leads to an early-onset hearing loss phenotype in both

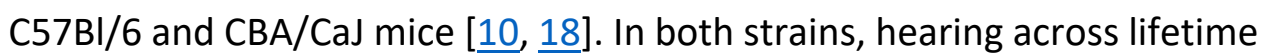
(hearing span) is reduced by more than $50 \%$ in $\mathrm{Ocm}$ knockout mice compared to wildtype [18-20]. There is no known hearing loss phenotype associated with targeted deletion of any other CaBP $[20,21]$. Downregulation of other CaBPs in favor of OCM during development, along with the hearing loss phenotype of $\mathrm{Ocm}^{-/-}$mice in the adult, leads us to hypothesize that OCM is compulsory for maintaining hearing function.

Here, we explore OCM-dependent $\mathrm{Ca}^{2+}$ dynamics in developing OHCs from ex vivo cochlear explants and in a transfected mammalian cell line. We

\section{2} signaling. These changes in $\mathrm{Ca}^{2+}$ signaling cannot be attributed to differences in the biophysical profiles of $\mathrm{Ocm}^{-/}$and $\mathrm{Ocm}^{+/-} \mathrm{OHCs}$. Although there are changes in APV and sorcin expression in response to loss of OCM, we conclude that they cannot compensate for OCM function. Experiments in cultured mammalian cells show that buffering by OCM differs from other $\mathrm{Ca}^{2+}$ buffers. Our results support the idea that OCM plays a unique and indispensable role as a $\mathrm{Ca}^{2+}$ buffer in developing $\mathrm{OHCs}$.

\section{Materials and methods}

\subsection{Animals}

The original $\mathrm{Ocm}$ mutant mouse $\left(\mathrm{C} 57 \mathrm{B1} / 6 \mathrm{Actb}^{\mathrm{Cre}} ; \mathrm{Ocm}^{\text {flox/flox }}\right)$ [18] was backcrossed onto the $\mathrm{CBA} / \mathrm{CaJ}$ and the $\mathrm{CBA} / \mathrm{CaH}$ background to minimize or eliminate any confounding effects of $C d h 23^{a h l}$ mutation, which is linked to hearing loss in the adult [10]. Confirmation of congenicity was done by whole genome scan (Jackson Laboratories, Bar Harbor, ME). To generate $\mathrm{Ocm}^{-/} ; \mathrm{Apv}^{-/-}$double mutants, $\mathrm{Ocm}^{-/}$mice were crossed with B6.129P2- 
Pvalbtm 1 Swal/J on the C57B1/6 background (Cdh23 $3^{\text {ahl }}$ mutation present) (Jackson Laboratories, Bar Harbor, ME). Animals were bred at the Baylor University Vivarium and at the animal facility of the University of Sheffield. Procedures performed in the UK and licensed by the Home Office under the Animals (Scientific Procedures) Act 1986 were approved by the University of Sheffield Ethical Review Committee. Experiments using $\mathrm{CBA} / \mathrm{CaH}$ mice were performed at the University of Sheffield, where mice were sacrificed via cervical dislocation in accordance with UK Home Office regulations. All other experiments were performed at Baylor University and the University of California, Los Angeles (UCLA). Neonatal animals (P3 or less) were given a lethal injection of sodium pentobarbital (100-150 ng/ $\mathrm{kg}$, IP) and immediately decapitated using scissors in accordance with US Public Health Service guidelines. For immunohistochemical analysis of adult mice, animals were given a lethal injection of sodium pentobarbital $(100-150 \mathrm{ng} / \mathrm{kg}$, IP) and transcardially perfused. For hearing function analysis, Distortion Product Otoacoustic Emissions (DPOAEs) were performed as previously described [18]. All procedures performed in the USA were approved by the Baylor Institutional and UCLA Animal Care and Use Committees (IACUC) as established by the US Public Health Service and performed in compliance with the National Institutes of Health animal care guidelines.

\subsection{Cloning}

The rat $\mathrm{Ocm}$ gene (sequence in Figure S01) was cloned into pcDNA3.1CFP and pEGFP-N1 FLAG (Addgene \#60360). Then, EGFPFLAG was removed using BamHI (NEB) and NotI (NEB) and replaced with the mCherry sequence (gene block of mCherry from Qiagen) to produce $\mathrm{pOcm}-\mathrm{mCh}$. Rat Apv and Sri (custom ordered gene block from IDT, Coralville, IA) (sequences in Figure S01) were swapped into the $\mathrm{Ocm}$ site using HindIII (NEB) /BamHI or HindIII/SalI to produce $\mathrm{p} A p v$-mCh and $\mathrm{pSri}$-mCh, respectively. The mCherry plasmid also replaces the FLAG 
linker with a flexible GS linker (SGGGGSGGGGSGGGGS) between Ocm;Apv;Sri and mCherry. The mCh control plasmid was generated by cloning out the $\mathrm{Ocm}$ gene from $\mathrm{Ocm}$-mCherry. Nucleotide sequences for rat Ocm;Apv;Sri and plasmid sequences for $\mathrm{pOcm}-\mathrm{CFP}$, pmCh, $\mathrm{pOcm}-\mathrm{mCh}$, $\mathrm{p} A p v-\mathrm{mCh}$ and $\mathrm{pSri-mCh}$ can be found in Figure S01.

127

\subsection{Cell Culture and Reagents}

Human Embryonic Kidney (HEK293T) cells were maintained in Dulbecco's Modified Eagle Medium (DMEM, Thermo Fisher) supplemented with $10 \%$ fetal bovine serum (FBS, Bio-techne) at $37 \mathrm{C}$ in a $5 \% \mathrm{CO}_{2}$ incubator. Transfections were performed using Lipofectamine 3000 (Thermo Fisher Scientific) in Opti-Mem reduced serum media (Thermo Fisher) according to manufacturer's protocol. Mammalian cells were transfected with either mCherry $(\mathrm{mCh}), A p v-\mathrm{mCh}, O c m-\mathrm{mCh}, \mathrm{Sri}$ $\mathrm{mCh}$, or $\mathrm{Ocm}$-CFP plasmids. 24 hours post transfection, growth media was replaced with HBSS (Gibco) before $\mathrm{Ca}^{2+}$ transient experiments.

\subsection{Single-cell electrophysiology}

$\mathrm{OHCs}$ from $\mathrm{CBA} / \mathrm{CaH} \mathrm{Ocm}^{+/-}$and $\mathrm{Ocm}^{-/-}$mice of both sexes were acutely dissected at P2 and P3. Cochleae were isolated from the inner ear as previously reported [22-25] using an extracellular solution composed of (in $\mathrm{mM}$ ): $135 \mathrm{NaCl}, 5.8 \mathrm{KCl}, 1.3 \mathrm{CaCl}_{2}, 0.9 \mathrm{MgCl}_{2}, 0.7 \mathrm{NaH}_{2} \mathrm{PO}_{4}, 5.6 \mathrm{D}-$ glucose, $10 \mathrm{HEPES}-\mathrm{NaOH}$. Sodium pyruvate $(2 \mathrm{mM})$, amino acids and vitamins were added from concentrates (Thermo Fisher Scientific, UK). The $\mathrm{pH}$ was adjusted to 7.5 (osmolality $\sim 308 \mathrm{mmol} \mathrm{kg}^{-1}$ ). The dissected cochleae were fixed at the bottom of the recording chamber by a nylonmeshed silver ring and perfused with the above extracellular solution. OHCs were viewed using an upright microscope (Olympus BX51) equipped with Nomarski Differential Interface Contrast (DIC) optics with a $60 \mathrm{x}$ water immersion objective and $15 \mathrm{x}$ eyepieces. 
Recordings were performed at room temperature $\left(21-24^{\circ} \mathrm{C}\right)$ using an

153

154

155

156

157

158

159

160

161

162

163

164

165

166

167

168

169

170

171

172

173

174

175

176

177

178

179

180

181

182 Optopatch amplifier (Cairn Research Ltd, UK). Patch pipettes were pulled from soda glass capillaries and the shank of the electrode was coated with surf wax (2-3 M $\Omega)$. Current and voltage responses were measured using the following intracellular solution: $145 \mathrm{mM} \mathrm{KCl,} 3 \mathrm{mM} \mathrm{MgCl}_{2}, 1 \mathrm{mM}$ EGTA$\mathrm{KOH}, \quad \mathrm{mM} 5 \mathrm{Na} 2 \mathrm{ATP}, 5 \mathrm{mM}$ HEPES-KOH, $10 \mathrm{mM}$ sodium phosphocreatine ( $\mathrm{pH}$ adjusted to 7.28 with $\mathrm{KOH}$; osmolality was $294 \mathrm{mmol}$ $\mathrm{kg}^{-1}$ ). Voltage clamp protocols are referred to a holding potential of -84 $\mathrm{mV}$. Data acquisition was performed using pClamp software (Axon Instruments, Union City, CA, USA) using a Digidata. Data were filtered at $2.5 \mathrm{kHz}$ (8-pole Bessel), sampled at $5 \mathrm{kHz}$, and stored on computer. Offline data analysis was performed using Origin software (OriginLab, Northampton, MA, USA). Membrane potentials reported were corrected for the uncompensated residual series resistance $\left(R_{\mathrm{S}}\right)$ and the liquid junction potential (LJP), which was $4 \mathrm{mV}$, measured between electrode and bath solutions.

\section{5. $\quad \mathrm{Ca}^{2+}$ imaging in neonatal OHCs}

Three methods were used to measure $\mathrm{Ca}^{2+}$ dynamics in neonatal OHCs. For measurements using $\mathrm{Ca}^{2+}$ indicator dye Fluo-4, $\mathrm{Ca}^{2+}$ transients were induced either by local application of $\mathrm{KCl}$ or via $\mathrm{KCl}$ superfusion. For measurements using ratiometric $\mathrm{Ca}^{2+}$ indicator dye Fura-2, $\mathrm{Ca}^{2+}$ transients were induced via $\mathrm{KCl}$ superfusion. For all three methods, organ of Corti spirals were prepared as described previously [26, 27]. The apical third of the cochlea, corresponding to the $6-12 \mathrm{kHz}$ region in the adult [28], was used.

For $\mathrm{OHC} \mathrm{Ca}^{2+}$ transients induced by local application of $\mathrm{KCl}$, cochlear spirals from P0 and P3 $\mathrm{Ocm}^{+/-}$and $\mathrm{Ocm}^{-/} \mathrm{CBA} / \mathrm{CaH}$ mice were harvested. Cochlear spirals were bathed in an extracellular solution composed of (in $\mathrm{mM}$ ): $135 \mathrm{NaCl}, 5.8 \mathrm{KCl}, 1.3 \mathrm{CaCl}_{2}, 0.9 \mathrm{MgCl}_{2}, 0.7 \mathrm{NaH}_{2} \mathrm{PO}_{4}, 5.6 \mathrm{D}-$ glucose, $10 \mathrm{HEPES}-\mathrm{NaOH}$. Sodium pyruvate $(2 \mathrm{mM})$, amino acids and 
vitamins were added from concentrates (Thermo Fisher Scientific, UK) [르, 29]. The $\mathrm{pH}$ was adjusted to 7.5 (osmolality $\sim 308 \mathrm{mmol} \mathrm{kg}^{-1}$ ). To access OHCs, Deiters' cells were removed via suction of a small pipette $(\sim 3-4 \mu \mathrm{m}$ in diameter) as described previously $[\underline{22}, \underline{25}]$. High $\mathrm{K}^{+}$solution used for local application was (in mM): $113 \mathrm{NaCl}, 1.3 \mathrm{CaCl}, 0.9 \mathrm{MgCl}_{2}, 40 \mathrm{KCl}, 10$ HEPES, 5.6 Glucose, $0.7 \mathrm{NaH}_{2} \mathrm{PO}_{4}\left(\mathrm{pH} 7.5\right.$, osmolality $\left.307 \mathrm{mmol} \mathrm{kg}^{-1}\right)$. For $\mathrm{Ca}^{2+}$ dye loading, organ of Corti preparations were incubated for $40 \mathrm{~min}$ at $37^{\circ} \mathrm{C}$ in DMEM/F-12 (Gibco), supplemented with Fluo-4 AM (final concentration 10-20 $\mu \mathrm{M}$; Thermo Fisher Scientific). The incubation medium contained pluronic F-127 (0.1\% w/v, Sigma-Aldrich, UK) and sulfinpyrazone $(250 \mu \mathrm{M})$ to prevent dye sequestration and secretion [27]. Preparations were transferred to a small microscope chamber, immobilized under nylon mesh, and brought to room temperature. To elicit $\mathrm{Ca}^{2+}$ transients, $\mathrm{a} \sim 7 \mathrm{~s}$ local application of $40 \mathrm{mM} \mathrm{KCl}$ was delivered from a pipette positioned adjacent to row $3 \mathrm{OHCs}$. $\mathrm{Ca}^{2+}$ signals were recorded using a two-photon laser-scanning microscope (Bergamo II System B232, Thorlabs Inc., USA) based on a mode-locked laser system operating at 800 nm, 80-MHz pulse repetition rate and $<100$-fs pulse width (Mai Tai HP DeepSee, Spectra-Physics, USA). Images were formed by a 60x objective, 1.1 NA (LUMFLN60XW, Olympus, Japan) using a GaAsP PMT (Hamamatsu) coupled with a 525/40 bandpass filter (FF02-525/40-25, Semrock). Using the two-photon microscope, fluorescence recording consisted of 4,000 frames taken at 30.3 frames per second from a $125 \times 125$ $\mu \mathrm{m}(512 \times 512$ pixels $)$ region.

For $\mathrm{OHC} \mathrm{Ca}{ }^{2+}$ transients induced by $\mathrm{KCl}$ superfusion, cochlear spirals were isolated from P3 $\mathrm{Ocm}^{+/} ; \mathrm{Apv}^{+/+}, \mathrm{Ocm}^{-/} ; \mathrm{Apv}^{+/+}$or $\mathrm{Ocm}^{-/} ; \mathrm{Apv}^{-/-}$mice (mixed $\mathrm{CBA} / \mathrm{CaJ}$ and $\mathrm{C} 57 \mathrm{Bl} / 6$ background), harvested, and prepared as described above. Cochlear spirals were bathed in a perilymph-like extracellular solution composed of (in $\mathrm{mM}$ ): $136.8 \mathrm{NaCl}, 5.8 \mathrm{KCl}, 0.4$ $\mathrm{KH}_{2} \mathrm{PO}_{4}, 0.3 \mathrm{Na}_{2} \mathrm{HPO}_{4}, 0.8 \mathrm{MgSO}_{4}, 1.3 \mathrm{CaCl}_{2}, 4.2 \mathrm{NaHCO}_{3}, 5 \mathrm{HEPES}$ and 5.6 glucose $\left(\mathrm{pH} 7.4-7.5\right.$, osmolality $\left.\sim 306 \mathrm{mmol} \mathrm{kg}^{-1}\right)$. $\mathrm{Ca}^{2+}$ signals were 
recorded using a custom-built confocal spinning disk (X-Light SDC with 6 laser lines, and a Photometrics sCMOS cooled camera) upright microscope (Leica, DM 6000 FS, Germany) with a 63x / 0.90 water immersion long working distance objective (Leica, 15506362 HCX APO L 63x/0.90 W UV-I CS2). Using the spinning disc confocal microscope, each $\mathrm{Ca}^{2+}$ fluorescence recording includes 1500 frames taken at 80 frames per second using VisiView (VISITRON). KCl-induced depolarization solution was applied using a Picospritzer for bath perfusion. The solution was composed of (in mM): $142.4 \mathrm{KCl}, 0.4 \mathrm{KH}_{2} \mathrm{PO}_{4}, 0.3 \mathrm{Na}_{2} \mathrm{HPO}_{4}, 0.8 \mathrm{MgSO}_{4}, 1.3 \mathrm{CaCl}_{2}$, 4.2 $\mathrm{NaHCO}_{3}, 5$ HEPES and 5.6 glucose (pH 7.4-7.5, osmolality $\sim 305 \mathrm{mmol}$ $\mathrm{kg}^{-1}$ ). Pressure was kept at a minimum $(<3$ psi) to avoid triggering mechanically induced $\mathrm{Ca}^{2+}$ signals.

To measure intracellular $\mathrm{Ca}^{2+}$ concentration using the ratiometric dye,

Fura-2, an upright Leica microscope (used above) was attached to a Lambda 10-B optical filter changer (Sutter instrument) with Lambda LS stand-alone xenon arc lamp (Sutter instrument), connected with $\mathrm{pE}$-universal collimator (CoolLED). Fura-2 (final concentration $10 \mu \mathrm{M}$, Invitrogen) was administered to dissected cochlear spirals bathed in extracellular medium containing 0.2\% F-127 (Invitrogen, USA). After 40 min incubation at 37 ${ }^{\circ} \mathrm{C}$, the cochlear spiral was transferred to the microscope chamber and washed with extracellular solution to remove dye from the cell membrane before imaging. Spirals were depolarized using $37 \mathrm{mM} \mathrm{KCl}$ administered via superfusion. The intracellular free $\mathrm{Ca}^{2+}$ concentration was calculated using the emission intensity ratio from Fura-2 via follow this equation:

$\mathrm{R}$ is the ratio of $510 \mathrm{~nm}$ emission intensity with excitation at $340 \mathrm{~nm}$ to

$$
\left[\mathrm{Ca}^{2+}\right]_{\mathrm{i}}=\mathrm{K}_{\mathrm{d}}{ }^{\mathrm{EGTA}} \times\left(\left[\mathrm{R}-\mathrm{R}_{\min }\right] /\left[\mathrm{R}_{\max }-\mathrm{R}\right]\right) \times\left(\left[\mathrm{F}^{380}{ }_{\max }\right] /\left[\mathrm{F}^{380}{ }_{\min }\right]\right)
$$
$510 \mathrm{~nm}$ emission intensity with excitation at $380 \mathrm{~nm}$. $R_{\min }$ is the ratio at zero free $\mathrm{Ca}^{2+}$. $\mathrm{R}_{\max }$ is the ratio at saturating $\mathrm{Ca}^{2+}$ (e.g., $39 \mu \mathrm{M}$ ). To measure the $\mathrm{F}^{380}{ }_{\max }$ and $\mathrm{F}^{380}{ }_{\min }$ in $\mathrm{OHC}, 25 \mu \mathrm{M}$ ionomycin was applied to get the 
saturating intracellular $\mathrm{Ca}^{2+}\left(\mathrm{F}^{380}{ }_{\max }\right)$, while $\mathrm{F}^{380}$ min in $\mathrm{OHC}$ was measured in $\mathrm{Ca}^{2+}$ - free solution with $1 \mathrm{mM}$ EGTA when $25 \mu \mathrm{M}$ ionomycin was applied. $\mathrm{K}_{\mathrm{d}}{ }^{\text {EGTA }}$ was calculated and calibrated using $\mathrm{Ca}^{2+}$ calibration buffer kit (Life technologies, USA). A double log calibration plot of Fura-2 was calculated using the equation $y=0.5634 x+3.7127$ with $R^{2}=0.9755$. The $\mathrm{Ca}^{2+}$ response of the indicator is linear with the $\mathrm{x}$-intercept being equal to the $\log$ of the apparent $\mathrm{K}_{\mathrm{d}}, 257.15 \mathrm{nM}$. The average of maximum $\mathrm{Ca}^{2+}$ concentration was calculated by the Fura- 2 ratio of $510 \mathrm{~nm}$ emission intensity with excitation at $340 \mathrm{~nm}$ to $510 \mathrm{~nm}$ emission intensity with excitation at $380 \mathrm{~nm}$.

Images were analyzed offline using custom-built software routines written in Python (Python 2.7, Python Software Foundation, RRID:SCR_014795) and ImageJ (NIH) [30]. $\mathrm{Ca}^{2+}$ signals were measured as relative changes of fluorescence emission intensity $\left(\Delta F / F_{0}\right) . \Delta F=\Delta F$ $F_{0}$, where $F$ is fluorescence at time $\mathrm{t}$ and $F_{0}$ is the fluorescence at the onset of the recording. After background subtraction, the activated OHCs were computed as pixel averages from square ROIs ( $\operatorname{size}=3.7 \mu \mathrm{m})$ centered on each OHC. Calcium transient rise-time constants were calculated using nonlinear regression in MATLAB using these equations $(x$ represents time while $y$ represents fluorescence intensity from each time point):

\section{6. $\quad \mathrm{Ca}^{2+}$ Transients of Transfected Mammalian Cells}

HEK293T cells were incubated with Fluo-4 (10 $\mu \mathrm{M}$, Invitrogen) for 30 (100 $\mu \mathrm{M}$, Sigma) was added to the perfusion chamber by a nearby pipette to induce $\mathrm{Ca}^{2+}$ transients. In a set of control samples, HEK293T cells were pre-incubated with cyclopiazonic acid $(\mathrm{CPA}, 10 \mu \mathrm{M})$, a SERCA inhibitor, to confirm that the source of $\mathrm{Ca}^{2+}$ was from ER stores [31]. A spinning disk confocal microscope was used to record changes in fluorescence over a 120 
s time period at a frame rate of 6.25 frames/s. HEK293T cells were transfected with CFP plasmids and incubated with Fluo-4. To prevent spectral overlap between fluorophores, images were captured sequentially using excitation band filters of 440 - $460 \mathrm{~nm}$ for CFP and $480-500 \mathrm{~nm}$ for Fluo-4 (Figure S02). A spinning disk confocal microscope was used to record changes in fluorescence over a $300 \mathrm{~s}$ time period at a frame rate of 1 frame/ $3 \mathrm{~s}$ for each filter. To categorize CFP expression levels, ROIs of individual cells were taken and fluorescence of cells (at least 100 for each group) were measured using ImageJ software. Data was transferred into MATLAB. Changes in fluorescence of single cells were plotted. Mean $\Delta F / F_{0}$ was calculated 30 seconds post-stimulation. Traces with obvious artifacts (e.g., due to motion) were removed from the analysis.

\subsection{RT-PCR}

Ocm-CFP transfected and non-transfected HEK293T cells were harvested and lysed using RLT buffer (Qiagen). RNA was isolated using the RNeasy plus mini kit (Qiagen). Reverse transcription reactions were performed using Transcriptor Reverse Transcriptase Kit (Roche). cDNA was subject to PCR using a Taq DNA Polymerase kit (Roche) using primers specific for mouse Ocm and Glyceraldehyde 3-Phosphodehydrogenase $(G 3 P D H)$. Primer sequences are provided in Figure S03. PCR cycling conditions were determined using the manufacturer's protocol. A negative (no template) control was included. PCR amplicons were run on a $2 \%$ agarose EtBr gel and imaged.

\section{8. $\quad q R T-P C R$}

Organ of Corti spirals were harvested from P0 and P3 CBA/CaJ mice, placed into RLT buffer (Qiagen), and immediately prepared for RNA extraction using the RNeasy Micro Kit (Qiagen) according to the manufacturer's protocol. cDNA was synthesized using iScript Reverse Transcription Supermix (BioRad) according to manufacturer's protocols. A 
BioRad CFX96 RT system was used to perform qRT-PCR using SsoAdvanced Universal SYBR Green (BioRad). $n=3$ technical replicates (i.e., 3 replicates for each sample per gene) were used for each plate. Expression levels for target genes were normalized to Beta-2-Microglobulin $(B 2 M)$, a cochlear reference gene [32]. Primer sequences can be found in Figure S03. Quantification of mRNA expression (fold change) from the $\mathrm{Cq}$ data was calculated using the $\Delta \Delta \mathrm{Cq}$ method [33]. In short, the mRNA expression level of a target gene was first normalized to the average mRNA expression level of the corresponding reference gene $(B 2 M)$ to obtain the $\Delta \mathrm{Cq}$ value. Then, the $\Delta \Delta \mathrm{Cq}$ of each gene was calculated using the following formula: $\Delta \mathrm{Cq}$ (target gene from sample) - $\Delta \mathrm{Cq}$ (target gene from P0 WT group). Then, $2^{-\Delta \Delta \mathrm{Cq}}$ was calculated to represent the relative mRNA expression (fold change). All values were normalized to the mean $\mathrm{Cq}$ value of $\mathrm{Ocm}^{+/-}$at P0. Raw qRT-PCR values and calculations can be found in

\subsection{Immunofluorescence}

Cochlea from neonatal CBA/CaJ mice (P0 and P3) were harvested and flushed with 4\% paraformaldehyde (PFA, Sigma). Cochlea surface preparations were placed in sucrose for 30 minutes with shaking, fixed in 4\% paraformaldehyde for 40 minutes, blocked with 5\% NHST (0.3\% Triton $\mathrm{X}-100$ ) for 1 hour at room temperature. Samples were stained with antibodies to OCM (Santa Cruz sc-7446, 1:200), APV (SWANT PVG-213, 1:200), and sorcin (Invitrogen PA5-64975, 1:200). Primary antibodies were incubated overnight at 37C. Phalloidin-iFluor 488 (Abcam ab176753, 1:1000) and appropriate Alexa Fluor (Thermo 1:200) and Northern Lights (R\&D Systems 1:200) conjugated secondary antibodies were incubated for 2 hours at $37^{\circ} \mathrm{C}$. Slides were prepared using Vectashield mounting media with DAPI (Vector Labs). 
Hearing function was measured via distortion product otoacoustic emissions (DPOAEs) as described previously [18, 34, 35]. 1 month-old $\mathrm{Ocm}^{+/+} ; \mathrm{Apv}^{+/+}, \mathrm{Ocm}^{-/-} ; \mathrm{Apv}^{+/+}$, and $\mathrm{Ocm}^{-/} ; \mathrm{Apv}^{-/-}$mice on $\mathrm{C} 57 \mathrm{Bl} / 6$ were used. Acoustic stimuli were delivered using a custom acoustic assembly previously described [36]. Sound level was raised in $10 \mathrm{~dB}$ steps from 10 $\mathrm{dB}$ below threshold up to $80 \mathrm{~dB}$ sound pressure level (SPL). The frequencies that were used are as follows: 5.66, 8.00, 11.32, 16.00, 32.00, and 45.26 kHz. The Eaton-Peabody Laboratories Cochlear Function Test Suite (EPLCFTS) was used to collect DPOAE input-output data and determine thresholds (f2 level required to produce a DPOAE at $0 \mathrm{~dB}$ SPL).

\subsection{Statistical analysis}

Statistical analysis was performed using GraphPad Prism 8 software. To compare means between two groups, an unpaired $t$ test was used. For data sets that were not normally distributed, a Mann-Whitney $U$ test was performed. When data was normally distributed, but standard deviations (SD) differed between groups, a Welch's $t$ test was used. To compare the means of three or more groups, an ANOVA was used. When normal distribution could not be assumed, a nonparametric Kruskal-Wallis test, followed by a Dunn's multiple comparisons test was performed. Animals of either sex were randomly assigned to the different experimental groups. No statistical methods were used to define sample size, which was selected based on previous published similar work from our laboratories. Animals were taken from multiple cages and breeding pairs unless otherwise indicated. The electrophysiological (but not imaging) experiments were performed blind to animal genotyping.

3.1. Ocm expression in the neonatal cochlea begins at P0

The maturation of $\mathrm{OHC}$ function follows the expression of a variety of channels, pumps and buffers that modulate levels of $\mathrm{Ca}^{2+}$ (Figure 1A). 
Although OCM is found throughout the cytoplasm in mature $\mathrm{OHCs}$, it shows strong immunoreactivity (ir) near the lateral membrane subsurface cisternae and overlaps extensively with prestin-ir (Figure 1B). However, prior to prestin expression and $\mathrm{OHC}$ maturation, $\mathrm{OCM}$ is diffusely located throughout the cytoplasm (Figure 1A). In previous studies, we detected Ocm mRNA expression from whole cochlea as early as P3 [14]. To determine more precisely the onset of $\mathrm{Ocm}$ expression in the organ of Corti, we performed qRT-PCR and immunofluorescence on microdissected organ of Corti spirals from P0 and P3 mice. Low levels of the Ocm mRNA transcript could be detected in $\mathrm{Ocm}^{+/-}$mice as early as $\mathrm{P} 0$, which then increased by approximately 9-fold by P3 (Figure 1C). While OCM-ir was absent at P0, P3 OHCs from $\mathrm{Ocm}^{+/}$mice showed low levels of OCM-ir, which varied in expression between individual cells (Figure 1D). As expected, OHCs from $\mathrm{Ocm}^{-/}$mice had negligible amounts of $\mathrm{Ocm}$ mRNA expression and OCM-ir (Figure 1C,D). OCM expression is, therefore, substantially upregulated in the $\mathrm{Ocm}^{+/-}$cochlea between P0 and P3, with diffuse and variable cytoplasmic distribution.

\subsection{Onset of OCM changes $\mathrm{Ca}^{2+}$ signaling in $\mathrm{OHCs}$}

After determining the onset of OCM protein expression in OHCs (between P0 and P3), we investigated how OCM expression influences $\mathrm{Ca}^{2+}$ signaling during early postnatal development. To measure this, we administered $\mathrm{Ca}^{2+}$ indicator dye, Fluo-4, to dissected cochlear preparations. adjacent to the $3^{\text {rd }}$ row of OHCs. The $\mathrm{Ca}^{2+}$-related change in fluorescence intensity was recorded as $\Delta F / F_{0}$.

At P0, OHCs showed spontaneous and rapid $\mathrm{Ca}^{2+}$ transients (Figures S05, S06). We have previously shown that these $\mathrm{Ca}^{2+}$ transients are abolished in $\mathrm{Ca}^{2+}$-free solution, indicating their dependence on extracellular $\mathrm{Ca}^{2+}[25]$. In addition to spontaneous activity, all three rows of OHCs from 
both $\mathrm{P} 0 \mathrm{Ocm}^{+/}$and $\mathrm{Ocm}^{-/}$mice responded to $\mathrm{KCl}$ application (Figure 2A,B, S05, S06). There was little to no difference in responses between $\mathrm{OHC}$ rows (Figure S04, S05) (only responses from the third row of OHC are shown). At P0, OHCs from $\mathrm{Ocm}^{+/}$and $\mathrm{Ocm}^{-/}$mice showed similar responses to local application of $\mathrm{KCl}\left(\mathrm{P} 0 \mathrm{Ocm}^{+/-} 9.44 \pm 0.72\right.$ vs $\mathrm{P} 0 \mathrm{Ocm}^{-/}$ $9.48 \pm 0.38)$. At this postnatal age, there was no difference in rise-time constants $(\tau)$ between $\mathrm{Ocm}^{+/-}$and $\mathrm{Ocm}^{-/-} \mathrm{OHCs}(t$ test) (Figure 2E).

In contrast to $\mathrm{P} 0, \mathrm{P} 3 \mathrm{OHCs}$ exhibited less spontaneous $\mathrm{Ca}^{2+}$ transient activity (Figure S07, S08), which is consistent with other studies [25, 37]. The rise $\tau$ were different between P3 $\mathrm{Ocm}^{+/}$and $\mathrm{Ocm}^{-/} \mathrm{OHCs}(t$ test, $p<0.001$ ) (Figure 2F). P3 $\mathrm{Ocm}^{+/-}$mice had a mean rise $\tau$ of $137.40 \pm 41.23$, which was significantly slower compared to aged-matched $\mathrm{Ocm}^{-/-} \mathrm{OHCs}$ that had a mean rise $\tau$ of $56.82 \pm 14.97$ (Figure 2F). Regardless of genotype, the mean rise $\tau$ was considerably faster in P0 OHCs compared to P3 OHCs ( $t$ test, $p<0.001$ ) (Figure 2G).

\subsection{Neonatal $\mathrm{Ocm}^{-/}$OHCs exhibit normal biophysical profiles}

We then investigated whether differences in $\mathrm{Ca}^{2+}$ signaling in P3 OHCs between $\mathrm{Ocm}^{+/-}$and $\mathrm{Ocm}^{-/-}$mice (Figure 3) had any effect on their biophysical properties by performing patch-clamp experiments. Potassium currents, which at this age are primarily carried by delayed rectifier $\mathrm{K}^{+}$ channels [22], were recorded while applying a series of hyperpolarizing and depolarizing voltage steps (in $10 \mathrm{mV}$ increments) from the holding potential of $-84 \mathrm{mV}$ (Figure 3A,B). The time-course and voltagedependence of the outward $\mathrm{K}^{+}$currents in OHCs were comparable between $\mathrm{Ocm}^{+/-}$and $\mathrm{Ocm}^{-/-}$mice (Figure 3A-C). The total outward $\mathrm{K}^{+}$current measured at $0 \mathrm{mV}$ was comparable between the two genotypes (Figure 3D). Voltage responses to current injections were also indistinguishable between the two genotypes, with action potentials being elicited by depolarizing current injections (Figure 3E,F), as previously shown [22]. The resting membrane potential of OHCs, which was obtained by the voltage-clamp 
recordings, was not significantly different between $\mathrm{Ocm}^{+/-}$and $\mathrm{Ocm}^{-/-}$mice (Figure 3G).

These experiments demonstrate that $\mathrm{OHCs}$ from $\mathrm{Ocm}^{-/}$mice have similar biophysical properties as those measured in control cells, indicating that the absence of OCM does not affect $\mathrm{OHC}$ electrophysiological function at these early postnatal ages.

3.4. Apv and Sri gene expression is altered in organ of Corti from

$\mathrm{Ocm}^{-/-}$mice

In some instances, the deletion of a particular $\mathrm{CaBP}$ is compensated for by a similar $\mathrm{CaBP}$ to maintain $\mathrm{Ca}^{2+}$ homeostasis [38-40]. For example, in the brain, OCM is upregulated in response to genetic deletion of $A p v$ [39]. Thus, we investigated whether the loss of OCM alters the expression of two other CaBPs highly expressed in OHCs: APV and sorcin.

First, we quantified the relative mRNA expression levels of Apv and Sri in dissected organ of Corti spirals from P0 and P3 $\mathrm{Ocm}^{+/-}$and $\mathrm{Ocm}^{-/-}$mice. $A p v$ transcript abundance was higher in $\mathrm{P} 0 \mathrm{Ocm}^{+/-}$mice compared to agematched $\mathrm{Ocm}^{-/}$mice, but this difference was not statistically significant $(t$ test, two-tailed) (Figure 4A). At P3, the two genotypes had similar levels of Apv mRNA. Sri mRNA levels were comparable between P0 $\mathrm{Ocm}^{+/}$and $\mathrm{Ocm}^{-/-}$mice (Figure 4B). At P3, $\mathrm{Ocm}^{-/-}$mice had two-fold lower Sri mRNA expression compared to $\mathrm{P} 3 \mathrm{Ocm}^{+/-}(t$ test $)$.

Using immunofluorescence, we investigated protein expression of APV and sorcin in organ of Corti spirals microdissected from P0 and P3 $\mathrm{Ocm}^{+/-}$ and $\mathrm{Ocm}^{-/}$mice. Generally, APV-ir was more abundant in IHCs compared to $\mathrm{OHCs}$ (Figure 4C). At P0, APV-ir is stronger in $\mathrm{Ocm}^{+/-} \mathrm{OHCs}$ and IHCs compared to age-matched $\mathrm{Ocm}^{-/}$mice. However, at P3, APV protein expression consistently showed an opposite trend, where APV-ir was increased in $\mathrm{OHCs}$ of $\mathrm{Ocm}^{-/}$compared to $\mathrm{OHCs}$ from $\mathrm{Ocm}^{+/-}$mice (Figure 4D). Next, we investigated the relative protein expression of sorcin. Overall, sorcin-ir was similar between IHCs and OHCs. At P0, less sorcin-ir was 
detected in $\mathrm{Ocm}^{-/} \mathrm{OHCs}$ and IHCs compared to $\mathrm{Ocm}^{+/}$(Figure 4D). At P3, $\mathrm{Ocm}^{-/-} \mathrm{OHCs}$ and IHCs express more sorcin protein compared to their $\mathrm{Ocm}^{+/}$littermates (Figure 4D), which is opposite of what was observed for Sri mRNA expression at P3. Interestingly, while $0 \mathrm{~cm}$ expression is minimal in IHCs [17], the absence of OCM gives rise to changes in APV and sorcin immunofluorescence in both OHCs and IHCs.

468

3.5. Loss of Apv further alters $\mathrm{Ca}^{2+}$ responses in $\mathrm{OHCs}$ from $\mathrm{Ocm}^{-/-}$ but does not affect hearing thresholds

Triple knockout of Apv, calbindin-D28k, and calretinin results in no observable hearing-related phenotype in 3-4-month-old mice [40]. Ocm is the only $\mathrm{CaBP}$ that when deleted, results in a hearing loss phenotype $[\underline{10}$, 18]. However, up until the onset of hearing loss, $\mathrm{Ocm}^{-/} \mathrm{OHCs}$ appear functional and intact. We investigated whether the presence of APV was sufficient for maintaining OHC function in the absence of OCM. We measured the hearing thresholds of single $\mathrm{Ocm}$ knockout and double $(O c m ; A p v)$ knockout mice. DPOAE thresholds are a standard way of assessing $\mathrm{OHC}$ function in vivo. We found that $\mathrm{Ocm}^{-/-} ; \mathrm{Apv}^{-/-}$mice did not have elevated hearing thresholds at 1-month of age compared to single $\mathrm{Ocm}$ knockouts $\left(\mathrm{Ocm}^{-/} ; \mathrm{Apv}^{+/+}\right)$(Figure S09). At $32 \mathrm{kHz}$, the $\mathrm{Ocm}^{-/-} ; \mathrm{Apv}^{-/-}$mice $(44.03 \pm 12.59 \mathrm{~dB}$ SPL) displayed DPOAE thresholds that fell in between $\mathrm{Ocm}^{+/+} ; \mathrm{Apv}^{+/+}(33.63 \pm 7.65 \mathrm{~dB}$ SPL$)$ and $\mathrm{Ocm}^{-/} ; \mathrm{Apv}^{+/+}(54.14 \pm 12.28 \mathrm{~dB}$ SPL) (Figure S09). The only significant difference in DPOAE thresholds was between $\mathrm{Ocm}^{+/+} ; \mathrm{Apv}^{+/+}$and $\mathrm{Ocm}^{-/} ; \mathrm{Apv}^{+/+}$mice $(\mathrm{p}=0.0021)($ one-way ANOVA). Without expression of OCM or APV, the OHCs of young adult $\mathrm{OCm}^{-/} ; \mathrm{Apv}^{-/-}$mice remain functional and loss of APV does not further elevate hearing thresholds.

Since APV is expressed at significant levels during early OHC development, we investigated whether $\mathrm{Ca}^{2+}$ signaling would be further altered with the deletion of both $O c m$ and $A p v$, together. We recorded $\mathrm{Ca}^{2+}$ transients from $\mathrm{OHCs}$ in acutely dissected cochlear spirals isolated from P3 
$\mathrm{Ocm}^{+/-} ; \mathrm{Apv}^{+/+}, \mathrm{Ocm}^{-/-} ; \mathrm{Apv}^{+/+}$, and $\mathrm{Ocm}^{-/-} ; \mathrm{Apv}^{-/-}$mice. Intact cochlear spirals required the use of $\mathrm{KCl}$ superfusion to elicit $\mathrm{Ca}^{2+}$ transients. OHCs from $\mathrm{OCm}^{+/-} ; \mathrm{Apv}^{+/+}$mice had the lowest magnitude of response to $\mathrm{KCl}$ superfusion compared to either $\mathrm{Ocm}^{-/-} ; \mathrm{Apv}^{+/+}$or $\mathrm{Ocm}^{-/-} ; \mathrm{Apv}^{-/-}$(Figure 5A, Figures S10-12). To maintain consistency with previous $\mathrm{Ca}^{2+}$ transient experiments, the change in fluorescence intensity as $\Delta F / F_{0}$ resulting from $\mathrm{KCl}$ superfusion was recorded from row $3 \mathrm{OHCs}$ only. As seen in Figure $\mathbf{5 A}$, the $\Delta F / F_{0}$ responses were highest for OHCs from $\mathrm{Ocm}^{-/-} ; \mathrm{Apv}^{+/+}$and $\mathrm{Ocm}^{-/-} ; \mathrm{Apv}^{-/-}$mice. The rise-time constants of the $\mathrm{KCl}$-induced $\mathrm{Ca}^{2+}$ signaling in $\mathrm{OHCs}$ from both $\mathrm{Ocm}^{-/-} ; \mathrm{Apv}^{+/+}$and $\mathrm{Ocm}^{-/-} ; \mathrm{Apv}^{-/-}$mice were significantly faster compared to control mice $\left(\mathrm{Ocm}^{+/-} ; \mathrm{Apv}^{+/+}\right)(p=0.0459$ and $p<0.0001$, respectively, one-way ANOVA, Figure 5B).

According to the experiments described above, loss of both $\mathrm{Ocm}$ and $A p v$ results in altered rise-time constants in $\mathrm{P} 3$ OHCs compared to the loss of $\mathrm{Ocm}$ alone. In order to quantify the levels of free intracellular $\mathrm{Ca}^{2+}$, we performed a similar set of experiments using the ratiometric $\mathrm{Ca}^{2+}$ indicator, Fura-2. First, we determined the double log calibration plot of Fura-2 (Figure S13). The $\mathrm{Ca}^{2+}$ response of the indicator was linear with an apparent $\mathrm{K}_{\mathrm{d}}$ of $257.15 \mathrm{nM}$. Second, cochlear spirals from P3 mice were harvested, incubated with Fura-2, and depolarized via $\mathrm{KCl}$ superfusion (see Materials and Methods). Finally, the average maximum $\left[\mathrm{Ca}^{2+}\right]_{\mathrm{i}}$ was calculated for each genotype. Maximum $\left[\mathrm{Ca}^{2+}\right]_{\mathrm{i}}$ from $\mathrm{Ocm}^{-/-} ; \mathrm{Apv}^{+/+}$and $\mathrm{Ocm}^{-/-} ; \mathrm{Apv}^{-/-}$were virtually identical. However, the maximum $\left[\mathrm{Ca}^{2+}\right]_{\mathrm{i}}$ of $\mathrm{Ocm}^{+/} ; \mathrm{Apv}^{+/+} \mathrm{OHCs}$ was almost 2-fold lower in comparison (Figure 5C) $(p=0.022$, one-way ANOVA). Taken together, we conclude that in $\mathrm{P} 3 \mathrm{OHCs}$, deletion of $\mathrm{Ocm}$ results in an increase in free cytosolic $\mathrm{Ca}^{2+}$. Further, while deletion of $A p v$ alters the kinetics of $\mathrm{Ca}^{2+}$ transients induced in $\mathrm{Ocm}^{-/-} \mathrm{OHCs}$, the total amount of freely available cytosolic $\mathrm{Ca}^{2+}$ is unchanged by additional deletion of $A p v$. 
To investigate the general buffering capacities of OCM, APV, and sorcin, we compared changes in $\mathrm{Ca}^{2+}$ signaling in HEK293T cells expressing the above fluorescently tagged proteins. HEK293T cells endogenously express sorcin, little or no APV, and no endogenous OCM (Human Protein Atlas). We confirmed expression of $\mathrm{Ocm}$-transfected HEK293T cells via RT-PCR (Figure 6A). First, we assessed the ability of OCM to buffer $\mathrm{Ca}^{2+}$ by inducing rises in intracellular $\mathrm{Ca}^{2+}$ waves with ATP, which stimulates release of $\mathrm{Ca}^{2+}$ from endoplasmic reticulum (ER) [41]. When stimulated with ATP, untransfected cells demonstrated a robust response compared to OCM expressing cells (Figure 6B). The ATP responses were abolished following depletion of intracellular $\mathrm{Ca}^{2+}$ stores by cyclopiazonic acid (CPA), consistent with previous reports [42], and confirm that the increases in cytosolic $\mathrm{Ca}^{2+}$ were from the ER.

Next, we assessed the ability of OCM to buffer $\mathrm{Ca}^{2+}$ in HEK293T cells by application of ionomycin, an ionophore that increases cytosolic $\mathrm{Ca}^{2+}$ levels from exogenous sources $[43, \underline{44}]$. mCherry (mCh)-tagged OCM, APV and sorcin plasmids were separately transfected into HEK293T cells. A flexible linker was inserted in between sequences encoding the aforementioned $\mathrm{CaBPs}$ and the fluorescent tag $(\mathrm{mCh})$ to more closely mimic the inherent binding kinetics of the proteins (see Figure S01 for plasmid maps and protein configurations). Cells expressing the control plasmid (mCh) displayed rapid and highly variable changes in fluorescence in response to stimulation with ionomycin that peaked between 20 and $30 \mathrm{~s}$ (Figure 6C,D). At 30 seconds post stimulation with ionomycin, $\mathrm{mCh}$ expressing cells had a mean $\Delta F / F_{0}$ of $2.25 \pm 1.82$ (Figure 6E). In contrast, we observed a very slow, gradual $\Delta F / F_{0}$ from cells expressing $O \mathrm{~cm}$-mCh, which, at 30 seconds post stimulation had a mean $\Delta F / F_{0}$ of $0.05 \pm 0.19$.

Ionomycin-induced responses of HEK293T cells transfected with APV $(0.21 \pm 0.40)$ and sorcin $(1.08 \pm 1.54)$ showed significant decreases in $\Delta F / F_{0}$ at $30 \mathrm{~s}$ post-stimulation compared to control $(p<0.0001$ for both comparisons, one-way ANOVA). (Figure 6E). Still, OCM expressing cells 
had the smallest variance and lowest $\Delta F / F_{0}$ at $30 \mathrm{~s}$ post-stimulation relative to both APV and sorcin expressing cells $(p=0.0173$ and $p<0.0001$, respectively). Although all three CaBPs reduced changes in fluorescence after ionomycin-induced $\mathrm{Ca}^{2+}$ flux, OCM was more effective than either APV or sorcin at minimizing changes in $\left[\mathrm{Ca}^{2+}\right]_{\mathrm{i}}$. The results from our mammalian cell culture experiments align with experiments performed with OHCs. We conclude that OCM lowers the amount of freely available $\left[\mathrm{Ca}^{2+}\right]_{\mathrm{i}}$ and increases the $\mathrm{Ca}^{2+}$ buffering capacity in HEK293T.

563

\section{Discussion}

565

We present the first direct evidence that OCM plays a unique and important role as a $\mathrm{Ca}^{2+}$ buffer in developing OHCs. While OHCs from $\mathrm{Ocm}^{-/-}$mice display normal membrane potentials and basolateral membrane currents, loss of OCM disrupts normal $\mathrm{Ca}^{2+}$ buffering dynamics. In $\mathrm{P} 0$ $\mathrm{OHCs}$, when OCM expression is minimal to non-existent, deletion of $\mathrm{Ocm}$ causes no major change in $\mathrm{Ca}^{2+}$ transient dynamics. However, at P3, the faster in $\mathrm{Ocm}^{-/-}$compared to age-matched control $\mathrm{Ocm}^{+/-}$mice. This indicates that during early stages of development, OCM plays a significant role in sculpting $\mathrm{Ca}^{2+}$ signaling in $\mathrm{OHCs}$, which has been shown to promote Deletion of both $O c m$ and $A p v$ further changes $\mathrm{OHC} \mathrm{Ca}^{2+}$ signaling, indicating that both OCM and APV shape $\mathrm{Ca}^{2+}$ dynamics in immature OHCs. Using a HEK293T cell culture model, we show that transiently expressed OCM rapidly buffers cytosolic $\mathrm{Ca}^{2+}$ more efficiently than either APV or sorcin. We conclude that OCM plays a significant role in the $\mathrm{Ca}^{2+}$ signaling network of immature OHCs.

In cochlear hair cells, EF-hand CaBPs are differentially regulated during the postnatal period. The present study found that $\mathrm{Ocm}$ mRNA expression turns on as early as P0, although at relatively low levels, and significantly increases by $\mathrm{P} 3$. This timeline is in accordance with RNA-seq analyses [45- 
49]. Our immunofluorescent analyses fall in line with previous studies, concluding that OCM protein expression increases during early postnatal OHC development, while APV expression decreases [12, 14]. Sorcin (soluble resistance-related calcium-binding protein) expression follows the same trend as APV. In control OHCs, we see a decrease in sorcin expression from P0 to P3. Recent studies show that sorcin is highly expressed in OHCs [17]. Sorcin is one of the most expressed $\mathrm{Ca}^{2+}$-binding proteins in the brain and cardiac tissues [50]. It is a key protein in the endoplasmic reticulum $\mathrm{Ca}^{2+}$-dependent cascades. In cardiac myocytes, sorcin regulates $\mathrm{Ca}^{2+}$ levels in the subsurface cisternae and inhibits $\mathrm{Ca}^{2+}$-induced $\mathrm{Ca}^{2+}$-release $[\underline{16}, \underline{17}]$. Sorcin likely plays a similar role in OHCs; however, its exact mechanism has yet to be defined.

Earlier studies suggest that genetic deletion of one EF-hand CaBP does not typically lead to the upregulation of other CaBPs [51]. However there are some exceptions to this rule, such as the upregulation of OCM in the brain of $\mathrm{Apv}^{-/-}$mice [ $[\underline{38}, \underline{39}]$. Our investigations in the cochlea suggest that CaBPs at early developmental stages. Protein expression of APV and sorcin is altered in cochleae of $\mathrm{Ocm}^{-/}$mice at both P0 and P3. However, the patterns in mRNA expression do not match the patterns observed in protein expression and the immunofluorescent changes are found in both OHCs and IHCs. At P3 the Sri mRNA expression decreases in the Ocm knockout whereas the sorcin-ir is more intense in Ocm knockout hair cells. There are multiple potential explanations for this. One possibility is that the lack of Ocm in P3 hair cells causes Sri expression to be differentially regulated in hair cells by some unknown post-transcriptional mechanism. Another possibility is that the mRNA expression studies are using whole tissues that include much more than just hair cells. In our qRT-PCR analysis, cochlear spirals are pooled, which include a diverse set of cells, all of which express Sri at high levels during development [48]. One benefit of immunofluorescent analysis is the ability to observe immunoreactivity in 
OHCs and IHCs, specifically. Although $\mathrm{Ocm}$ is preferentially expressed in $\mathrm{OHCs}$, there is a developmentally transient and minimal expression of $\mathrm{Ocm}$ in IHCs $[\underline{12}, \underline{17}]$. Here, we show that deletion of Ocm causes changes in sorcin immunofluorescence both in OHCs and IHCs. Thus, the presence of Ocm in IHCs, although relatively low, may contribute to the developmental expression of other CaBPs.

The dynamic changes in gene expression of OCM and APV during postnatal development suggest that these CaBPs may contribute to shaping the $\mathrm{Ca}^{2+}$ signaling network of OHCs in different ways. Here, the contribution of OCM in maintaining $\mathrm{OHC} \mathrm{Ca}{ }^{2+}$ homeostasis is highlighted in two ways: 1) At P0, before the onset of OCM expression, genetic deletion of $\mathrm{Ocm}$ has no effect on $\mathrm{Ca}^{2+}$ transients and 2) genetic deletion of $\mathrm{Ocm}$ at $\mathrm{P} 3$ causes considerable changes in $\mathrm{Ca}^{2+}$ rise-time kinetics. These changes in $\mathrm{Ca}^{2+}$ signaling cannot be attributed to differences in biophysical profiles. Regardless of any attempted compensational mechanisms, loss of $\mathrm{Ocm}$ leads to dysregulated $\mathrm{Ca}^{2+}$ signaling in OHCs. The present study suggests that APV also contributes somewhat to shaping $\mathrm{Ca}^{2+}$ transients in $\mathrm{OHCs}$ at P3. In the absence of OCM, the additional loss of APV leads to a further decrease in $\mathrm{OHC}$ rise-time kinetics. However, in $\mathrm{Ocm}^{-/-} \mathrm{OHCs}$, loss of $\mathrm{Apv}$ does not appear to contribute to the total maximum $\left[\mathrm{Ca}^{2+}\right]_{\text {i }}$ measured in P3 between OCM and APV. APV is considered a slow-onset $\mathrm{Ca}^{2+}$ buffer [51], while OCM has not yet been defined as a slow- or fast-onset buffer. identity, molecular weights, and tertiary structures [10], at least in HEK293T cells, the two proteins demonstrate differences in $\mathrm{Ca}^{2+}$ buffering capacity. OCM and APV are distinguished by their metal ion binding properties [21, $\underline{35}, \underline{52-54}]$. Rapid $\mathrm{Ca}^{2+}$ buffering by OCM is supported by our mammalian cell culture model. We observe a slow, gradual $\Delta F / F_{0}$ in OCM expressing cells following treatment with ionomycin or ATP. While ionomycin causes increases in cytosolic $\mathrm{Ca}^{2+}$ levels from exogenous sources 
$[\underline{43}, \underline{44}]$, ATP increases cytosolic $\mathrm{Ca}^{2+}$ through an intracellular mechanism. ATP induces $\mathrm{Ca}^{2+}$ transients in HEK293T cells via P2Y receptors in an inositol triphosphate $\left(\mathrm{IP}_{3}\right)$-dependent manner [41, 55-60]. Pre-treatment with cyclopiazonic acid (CPA), a SERCA inhibitor, abolishes the change in fluorescence of the $\mathrm{Ca}^{2+}$-indicator dye seen with ATP-treatment, confirming that the rise in cytoplasmic $\left[\mathrm{Ca}^{2+}\right]_{\mathrm{i}}$ levels is caused by release of $\mathrm{Ca}^{2+}$ from ER stores [31]. OCM effectively buffers cytosolic $\mathrm{Ca}^{2+}$ levels, buffers $\mathrm{Ca}^{2+}$ more effectively than either APV or sorcin.

While loss of Ocm alters Apv and Sri expression during development, these changes are ineffective in maintaining $\mathrm{Ca}^{2+}$ homeostasis over time, since young adult mice show accelerated age-related hearing loss [10, 18$]$. Other components of the $\mathrm{Ca}^{2+}$ signaling network, such as $\mathrm{Ca}^{2+}$ channels, development of the subsurface cisternae, localization of mitochondria, etc. may also be influenced by loss of $\mathrm{Ocm}$. It would be worthwhile to explore these mechanisms and determine whether they are consequences of $\mathrm{Ocm}$ mechanisms that attempt to restore $\mathrm{Ca}^{2+}$ homeostasis. The dysregulated lead to $\mathrm{Ca}^{2+}$ overload in adult $\mathrm{OHCs}$, which may be linked to the progressive early-onset hearing loss phenotype observed in young adult mice [18]. We

671 of $\mathrm{Ca}^{2+}$ signaling in OHCs.

\section{Author Contributions}

\section{Author Agreement}

$$
\text { All authors have read and approved the final version. }
$$

DS and WM designed, planned and supervised the research. KM and YY contributed equally to experimental design and implementation of the work. DS, WM, FC, YY, and SD performed $\mathrm{Ca}^{2+}$ transient experiments. FC, JJ, and WM performed electrophysiology experiments. YY, FJ, and JC 
performed qRT-PCR and immunofluorescence. KM and LC performed cloning and cell culture. LC, YY, and AH bred and maintained mouse colonies. LC performed hearing tests. YY, FC, JJ, FJ, WM, and DS analyzed the data. FC, YY and DS wrote and implemented code for data analysis. KM, YY, and DS wrote the paper. All authors contributed to the editing of the paper.

\section{CRediT authorship contribution statement}

Kaitlin Murtha: Investigation, Writing - Original Draft, Writing Review \& Editing, Visualization. Yang Yang: Methodology, Software, Validation, Formal analysis, Investigation, Writing - Review \& Editing, Visualization. Federico Ceriani: Methodology, Validation, Formal Analysis, Investigation, Writing - Review \& Editing. Jin-Yi Jeng: Methodology, Validation, Formal Analysis, Investigation, Writing Review \& Editing. Leslie Climer: Conceptualization, Investigation, Writing - Review \& Editing, Supervision, Project administration. Forrest Jones: Investigation, Writing - Review \& Editing. Jack Charles: Investigation, Writing - Review \& Editing. Sal Davana: Investigation, Writing - Review \& Editing. Aubrey Hornak: Project administration, Investigation, Writing - Review \& Editing. Walter Marcotti: Conceptualization, Methodology, Software, Resources, Writing - Review \& Editing, Supervision, Project administration, Funding acquisition. Dwayne Simmons: Conceptualization, Methodology, Formal analysis, Investigation, Resources, Data Curation, Writing - Original Draft, Writing - Review \& Editing, Visualization, Supervision, Project administration, Funding acquisition.

\section{Declaration of Competing Interest}

The authors declare that there are no conflicts of interest.

\section{Acknowledgements}

This research was supported by National Institute on Deafness and Other Communication Disorders Grants DC013304 and DC018935 (DDS), 2015-2016 Fulbright U.S. Scholar Award 5403 (DDS), American Hearing Research Foundation grant, the BBSRC BB/T004991/1 (WM). 
Figures

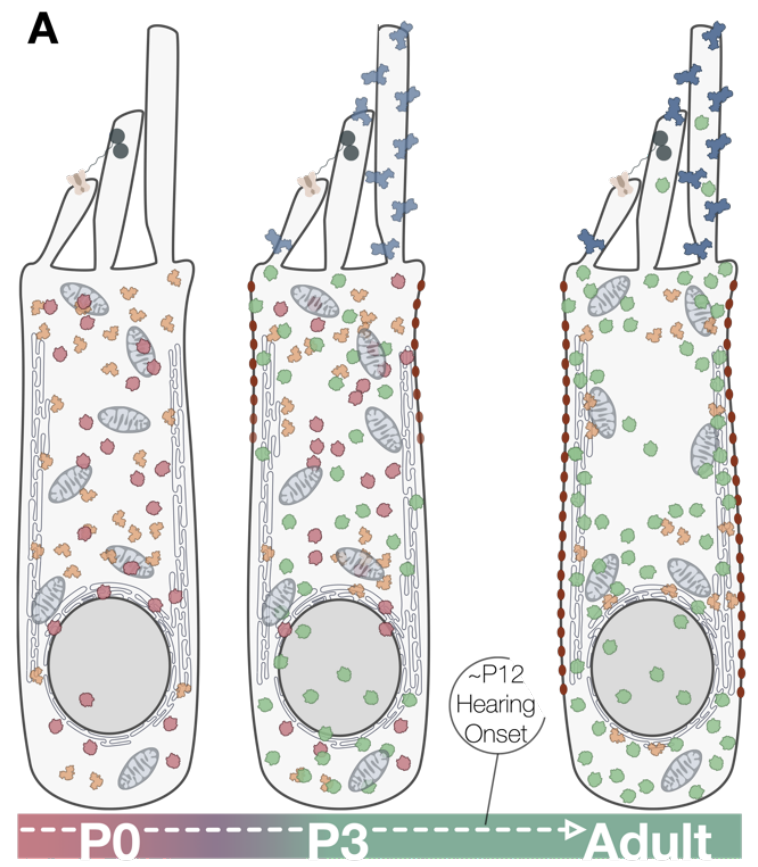

B

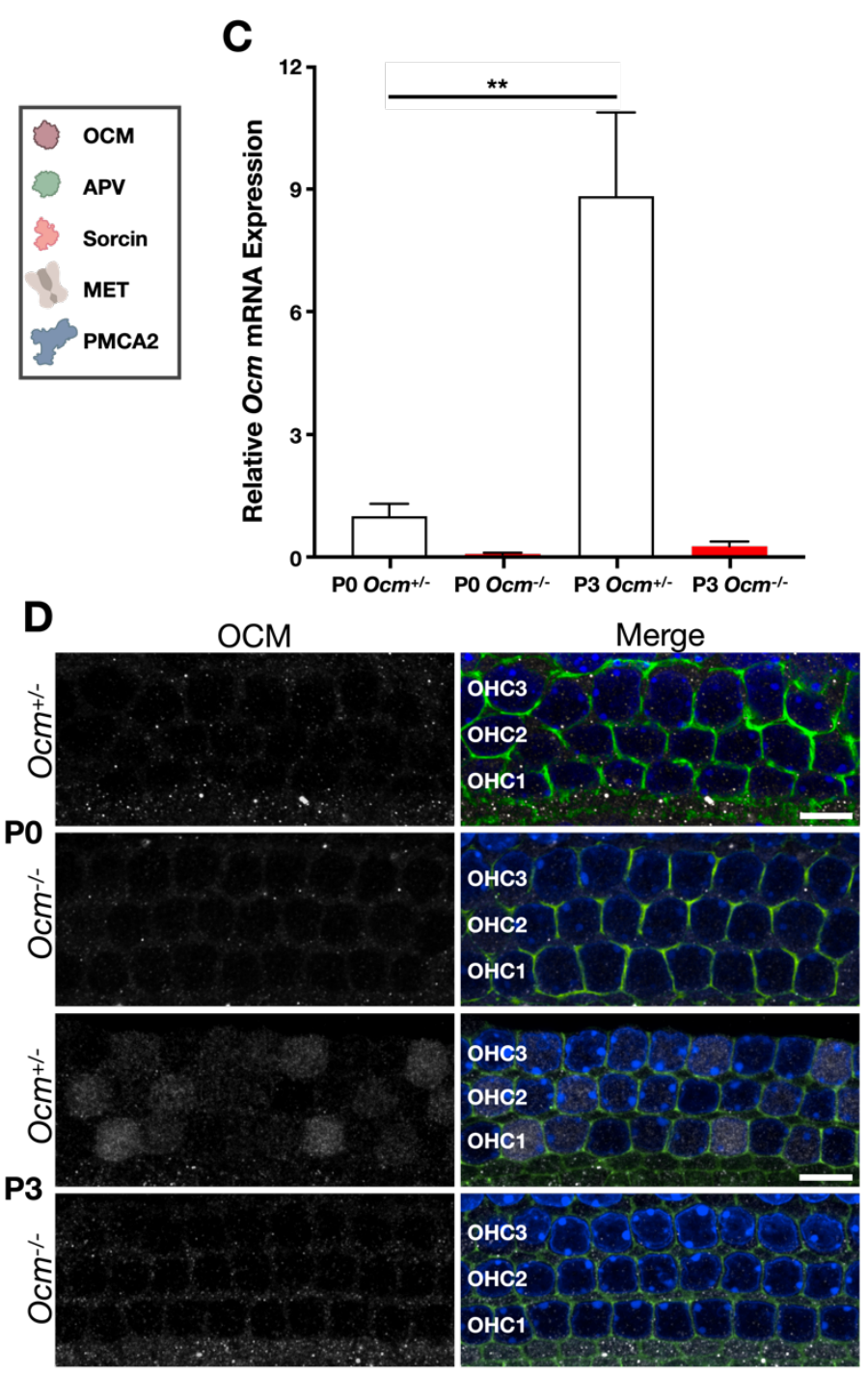

Figure 1. Expression of OCM begins early in development in mouse OHCs. A) Graphical timeline illustrating changes in the expression of $\mathrm{Ca}^{2+}$ related genes during $\mathrm{OHC}$ development (key on right). At $\mathrm{P} 0$, APV (red) expression is abundant [38]. Sorcin (orange) expression is also observed. By P3, OCM (green) protein expression is upregulated, while APV expression is downregulated [38]. B) Maximum Intensity Projection of mid-modiolar organ of Corti preparation from adult mouse (3 mo.). Sample was stained with OCM (white), prestin (red), phalloidin (green) and DAPI (blue). Inset shows details of OHC sub-nuclear region. C) Relative $\mathrm{Ocm}$ transcript levels measured via qRT-PCR in P0 and P3 $\mathrm{Ocm}^{+/-}$and $\mathrm{Ocm}^{-/-}$mice. Bars represent mean transcript levels (normalized to $B 2 M$, a housekeeping gene) and are plotted relative to P0 $\mathrm{Ocm}^{+/}$. Error bars represent S.E.M. Significance $(t$ test $)$ is denoted as: ${ }^{* *} p=0.005$. D) Confocal images of cochlear spirals harvested from $\mathrm{P} 0$ and $\mathrm{P} 3 \mathrm{Ocm}^{+/-}$and $\mathrm{Ocm}^{-/-}$mice. OCM (white), phalloidin (green) and DAPI (blue) are shown. Scale bar $=10 \mu \mathrm{m}$. Maximum Intensity Projections are composed of $2 \times 1 \mu \mathrm{m}$ slices. 63x magnification. 

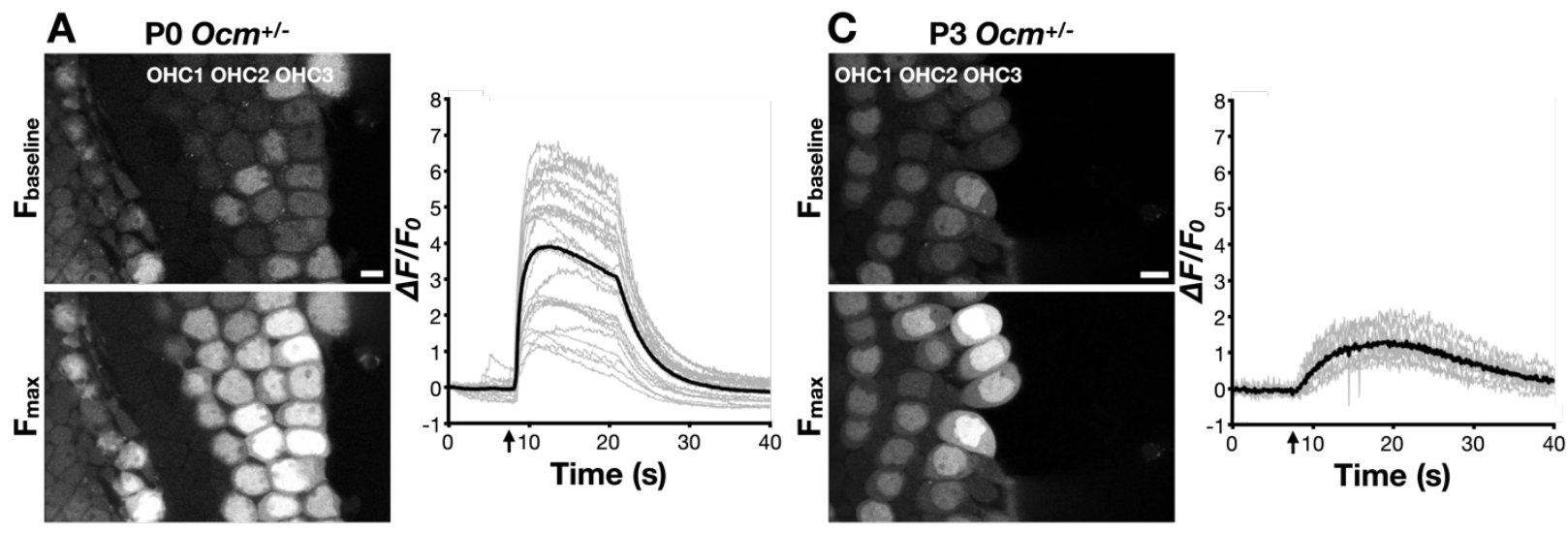
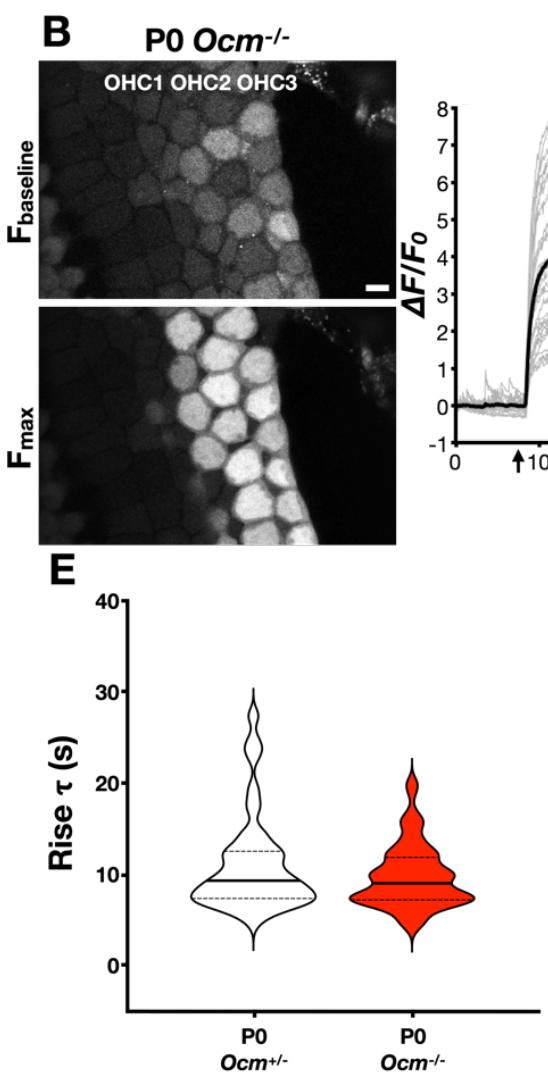

Figure 2. Calcium transients are induced by local application of $\mathrm{KCl}$ in $\mathrm{P0}$ and $\mathrm{P3} \mathrm{Ocm}^{+/-}$and $\mathrm{Ocm}^{-/-}$ OHCs. Acute organ of Corti preparations from P0 and P3 CBA/CaH mice were incubated with Fluo-4 and administered a local application of $\mathrm{KCl}$. Representative images depict $\mathrm{F}_{\text {baseline }}$ (before stimulation with $\mathrm{KCl}$ ) and $\mathrm{F}_{\max }$ (maximum change in fluorescence). Scale bar $=10 \mu \mathrm{m}$. To the right are $\Delta F / F_{0}$ plots for each genotype and age. Grey lines are $\Delta F / F_{0}$ measurements from individual OHCs. Solid black lines represent the mean $\Delta F / F_{0}$ for that preparation. Local application of $\mathrm{KCl}$ (arrow) was administered to $\left.\mathbf{A}\right) \mathrm{P} 0 \mathrm{Ocm}^{+/} \mathbf{B}$ ) P0 $\mathrm{Ocm}^{-/-}$C) P3 $\mathrm{Ocm}^{+/-}$and D) P3 $\mathrm{Ocm}^{-/-}$mice. Fluorescent transients were restricted to $\mathrm{OHC} 3(\mathrm{OHC}$ row 3). E-G) Violin plots from $\mathrm{KCl}$ induced $\mathrm{Ca}^{2+}$ transient experiments in $\mathrm{OHCs}$ from $\mathrm{P} 0$ and $\mathrm{P} 3 \mathrm{Ocm}^{+/-}$(white) and $\mathrm{Ocm}^{-/}$(red). Solid lines represent medians. Dotted lines represent quartiles. E) Rise $\tau$ from P0 $\mathrm{Ocm}^{+/-}$ $(\mathrm{n}=55 \mathrm{OHCs})$ and $\mathrm{Ocm}^{-/} \mathrm{OHCs}(\mathrm{n}=55 \mathrm{OHCs})$. F) Rise $\tau$ from P3 $\mathrm{Ocm}^{+/-}(\mathrm{n}=31 \mathrm{OHCs})$ and $\mathrm{Ocm}^{-/-} \mathrm{OHCs}$ $(\mathrm{n}=21 \mathrm{OHCs})$ G) Rise $\tau$ compared between $\mathrm{Ocm}^{+/-}$and $\mathrm{Ocm}^{-/ /} \mathrm{P} 0$ and P3 OHCs. Significant differences (Mann-Whitney test) denoted as follows: ${ }^{* *} p<0.0001$. 

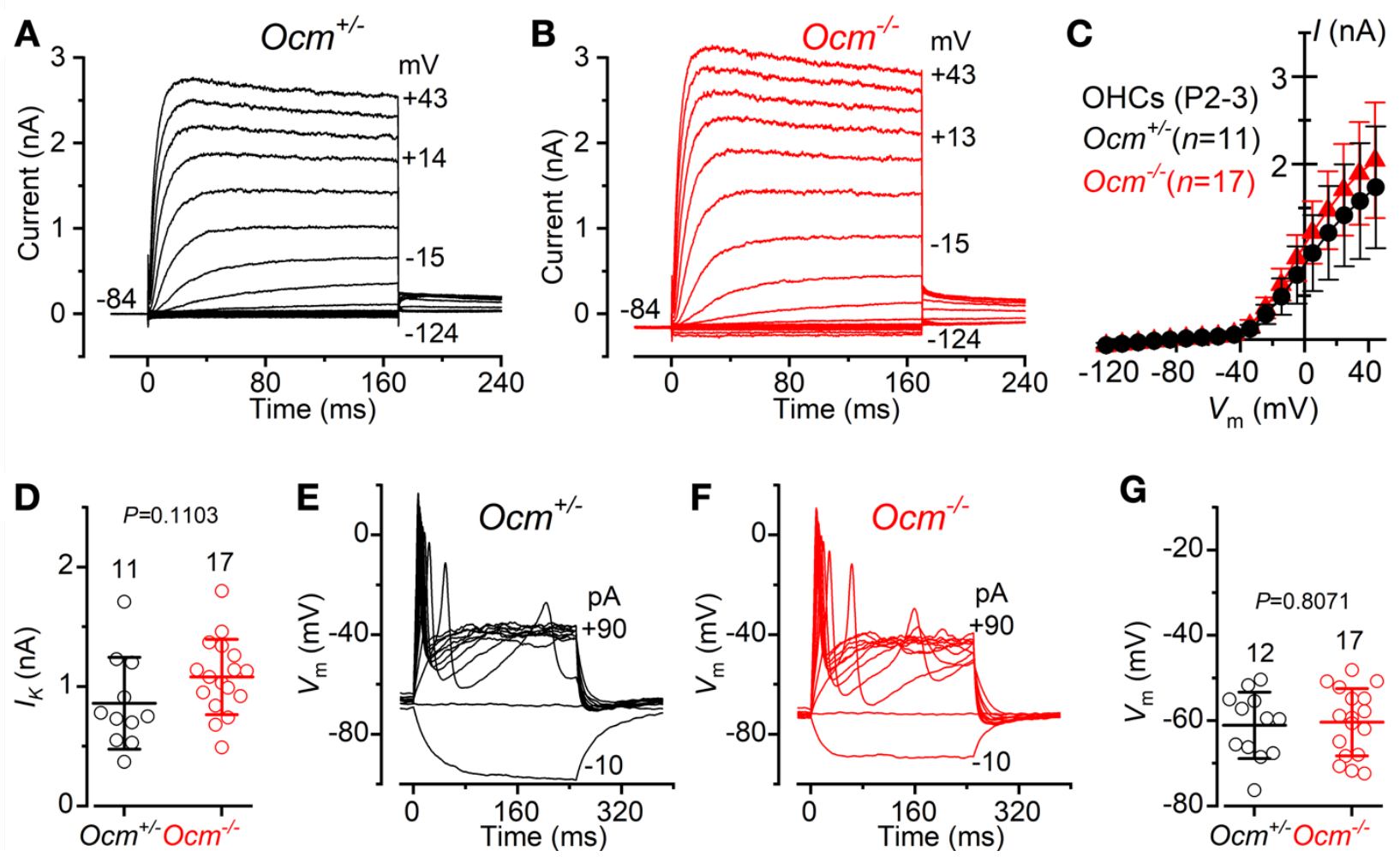

Figure 3. The biophysical properties of OHCs are not affected in early postnatal $\mathrm{Ocm}^{-/}$mice. $\mathrm{K}^{+}$ currents from $\mathrm{OHCs}$ of $\mathrm{P} 3 \mathrm{~A}$ ) $\mathrm{Ocm}^{+/}$and B) $\mathrm{Ocm}^{-/} \mathrm{CBA} / \mathrm{CaH}$ mice. Recordings were performed by applying a series of voltage steps in $10 \mathrm{mV}$ nominal increments from the holding potential of $-84 \mathrm{mV}$. C) Average current-voltage curves from OHCs of P2-P3 $\mathrm{Ocm}^{+-}$and $\mathrm{Ocm}^{-/}$. D) The size of the total steadystate outward $\mathrm{K}^{+}$current in $\mathrm{OHCs}$, which was measured at $0 \mathrm{mV}$ from the holding potential of $-84 \mathrm{mV}$, was not significantly different between $\mathrm{Ocm}^{+/}$and $\mathrm{Ocm}^{-/-}(p=0.1103, t$ test). Voltage responses elicited by applying a series of $10 \mathrm{pA}$ depolarizing current injections to $\mathrm{OHCs}$ of P3 $\mathrm{Ocm}^{+/}$E) and $\left.\mathrm{Ocm}^{-/} \mathbf{F}\right)$ mice. G) Resting membrane potential recoded from OHCs of P2-P3 $\mathrm{Ocm}^{+/}$and $\mathrm{Ocm}^{-/-}$mice. Values were not significantly different between the two genotypes $(p=0.8071, t$ test). Single value recordings are shown as open symbols. The number of OHCs measured is shown above the average data points. 

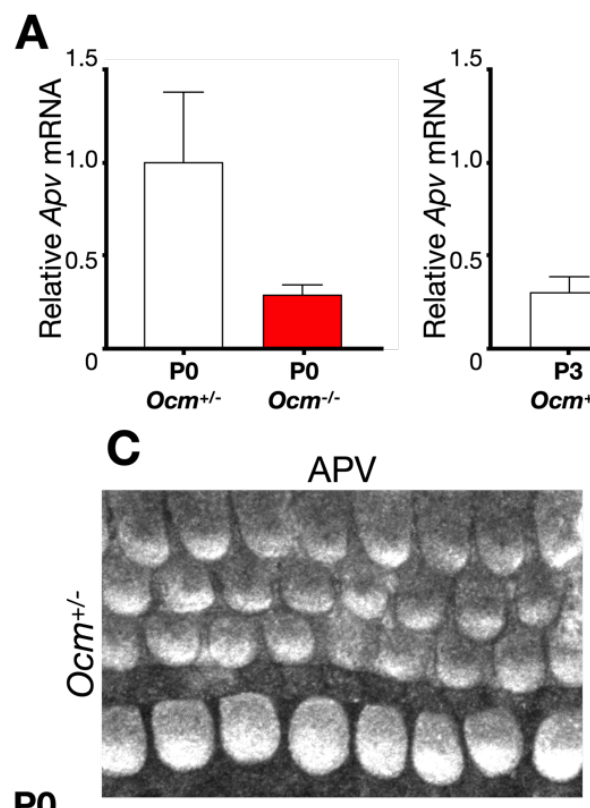

PO
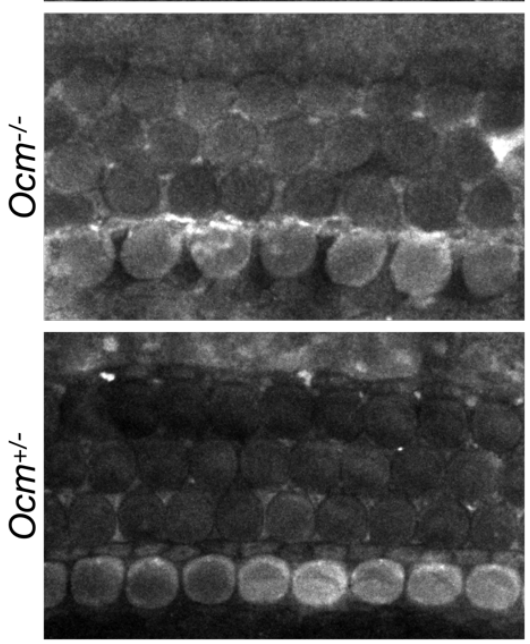

P3

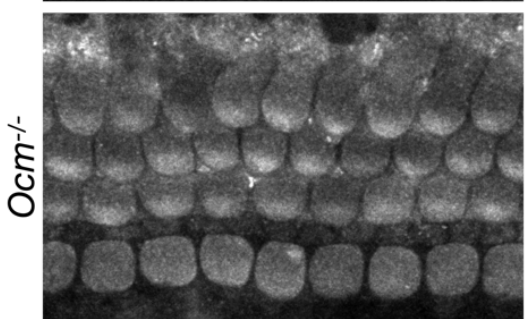

B

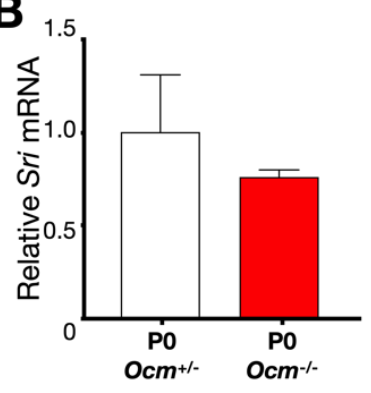

D

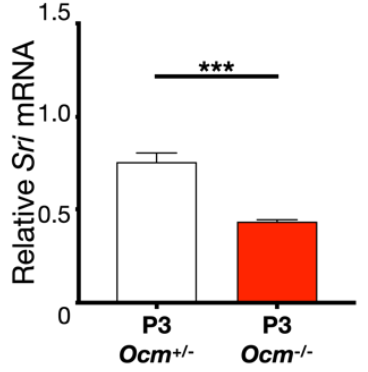

phalloidin
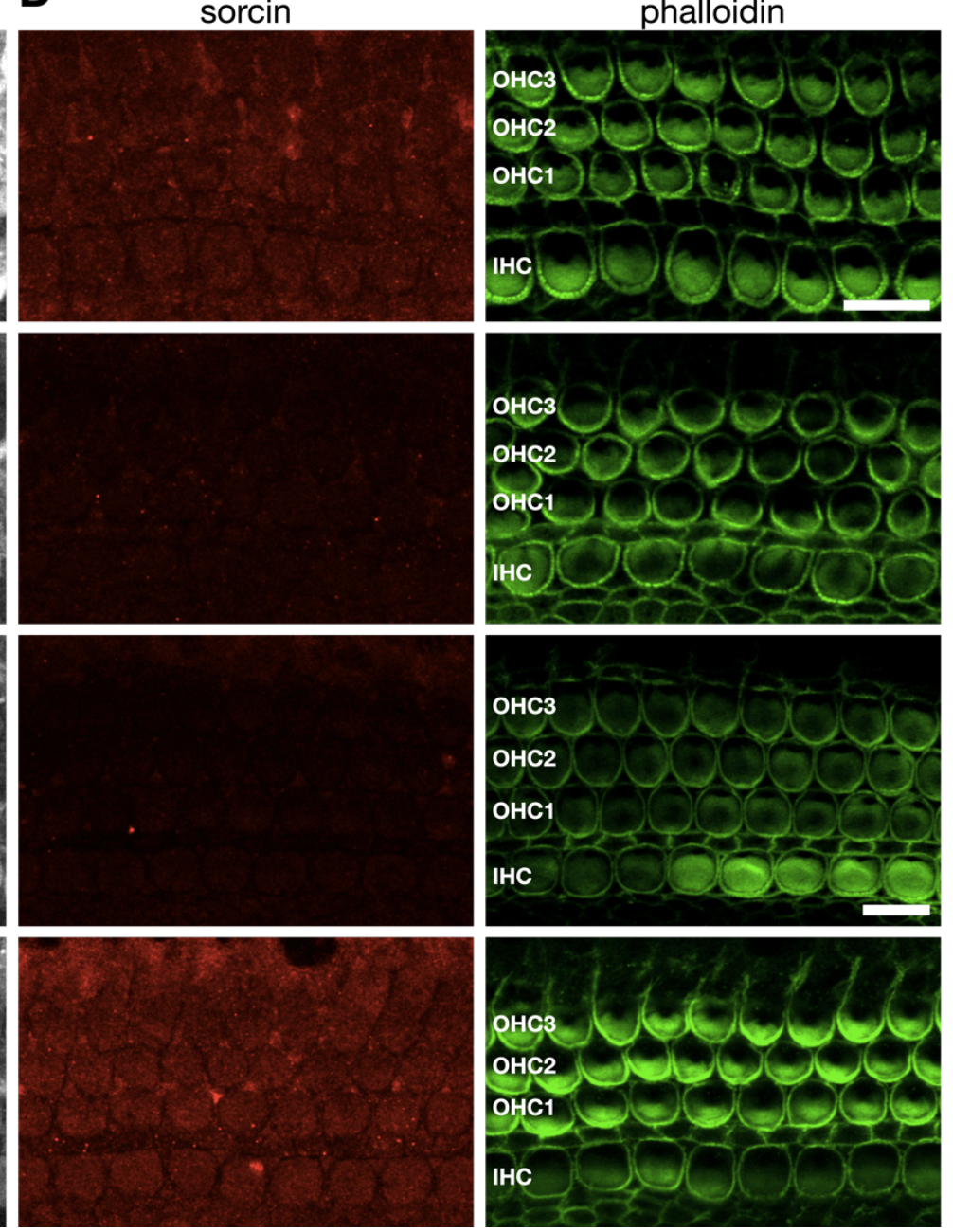

Figure 4. Absence of $\boldsymbol{O c m}$ alters APV and sorcin protein expression levels. A-B) qRT-PCR was used to determine relative transcript levels in cochlear spirals harvested from $\mathrm{P} 0$ and $\mathrm{P} 3 \mathrm{Ocm}^{+/-}$(white) and $\mathrm{Ocm}^{-}$ ${ }^{\prime}$ (red) mice. Mean values of relative normalized expression of A) Apv and B) Sri are represented by a bar graph. Mean transcript levels are plotted relative to $\mathrm{P} 0 \mathrm{Ocm}^{+/-}$mean values. Error bars represent S.E.M. Significance ( $t$ test) is denoted as: ${ }^{* * *} p<0.001$. Of note, when a one-tailed t test was used to compare mean values of $A p v$ mRNA abundance between $\mathrm{P} 0 \mathrm{Ocm}^{+/-}$vs $\mathrm{Ocm}^{-/-}$, there is a significant difference $(p=0.048)$ C-D) Confocal images of cochlear spirals microdissected from P0 and P3 $\mathrm{Ocm}^{+/-}$and $\mathrm{Ocm}^{-/-}$mice. C) APV (white) and D) sorcin (red) were detected at P0 and P3 in both $\mathrm{Ocm}^{+/-}$and $\mathrm{Ocm}^{-/-}$mice. Phalloidin and DAPI (not shown) were used to outline OHCs and denote subcellular location. Maximum Intensity Projections of $1 \mu \mathrm{m}$ slices starting from the cuticular plate and ending in the nucleus are shown here. Scale bar $=10 \mu \mathrm{m}$. 

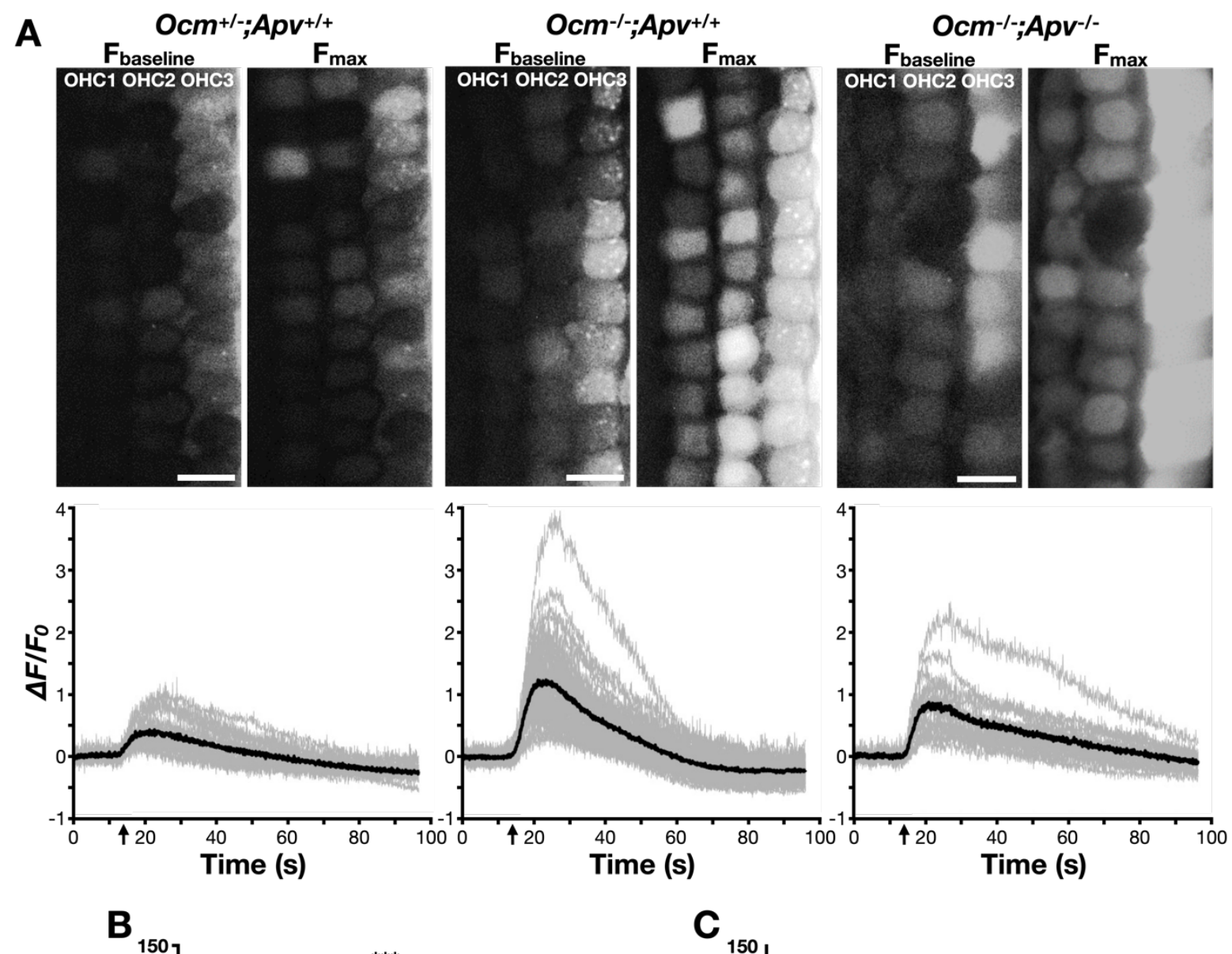

B
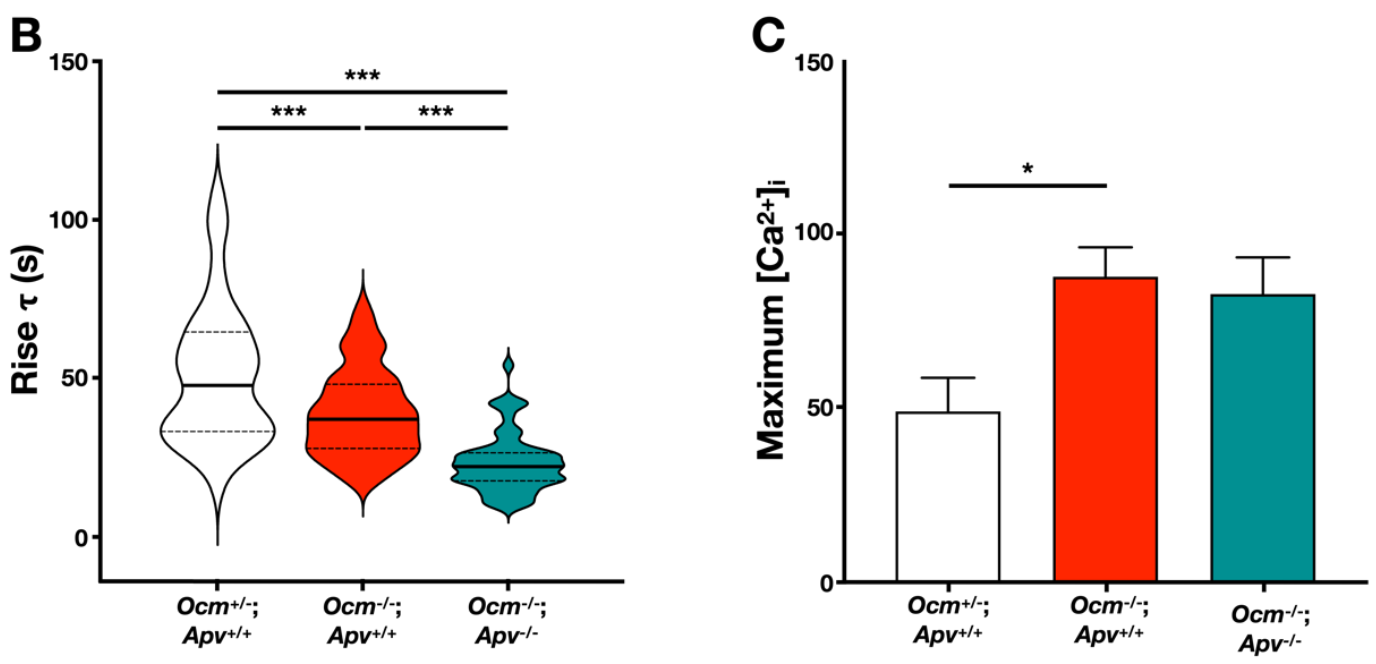

Figure 5. Calcium transients are altered in double $\mathrm{Ocm}$ and $A p v$ knockout OHCs. A) Representative images depict $\mathrm{F}_{\text {baseline }}\left(\right.$ left: before stimulation with $\mathrm{KCl}$ ) and $\mathrm{F}_{\max }$ (right: max change in fluorescence). Scale bar $=10 \mu \mathrm{m}$. Below $\Delta F / F_{0}$ is plotted for each genotype. Grey lines are $\Delta F / F_{0}$ measurements from individual OHCs. Solid black line represents the mean $\Delta F / F_{0}$ for that preparation. B) Violin plots of rise $\tau$ for $O \mathrm{~cm}^{+/-}$ $; \mathrm{Apv}^{+/+}$(white), $\mathrm{Ocm}^{-/-} ; \mathrm{Apv}^{+/+}$(red), $\mathrm{Ocm}^{-/} ; \mathrm{Apv}^{-/-}$(teal). n=3 animals per genotype. Solid lines represent medians. Dotted lines represent quartiles. Significant differences (one-way ANOVA) are denoted as follows: $* * * p<0.001)$. C) Fura-2 was used to estimate the $\left[\mathrm{Ca}^{2+}\right]_{\mathrm{i}}$ levels (in nM) of $\mathrm{Ocm}^{+-} ; \mathrm{Apv}^{+/+}$(black, $\mathrm{n}=38 \mathrm{OHCs}$ ) and $\mathrm{Ocm}^{-/} ; \mathrm{Apv}^{+/+}$(red, n=36 OHCs), and $\mathrm{Ocm}^{-/-} ; \mathrm{Apv}^{-/-}$(teal, $\left.\mathrm{n}=33 \mathrm{OHCs}\right)$. Significance (one-way ANOVA) 
A

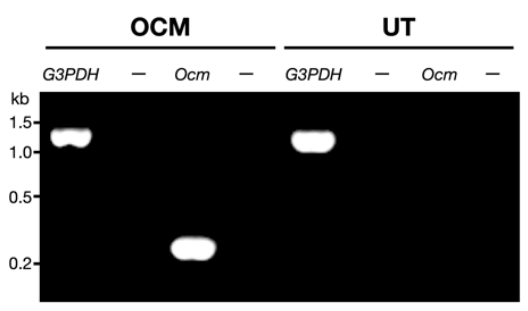

C

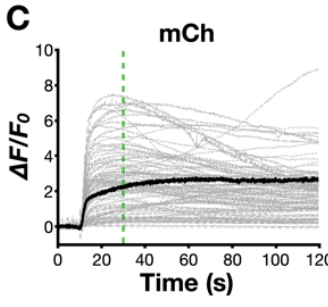

D
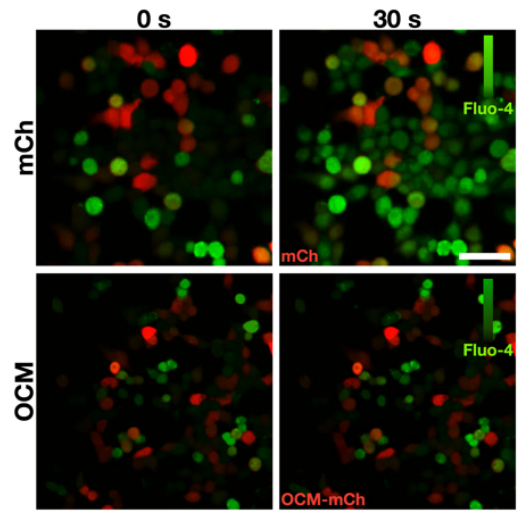

B
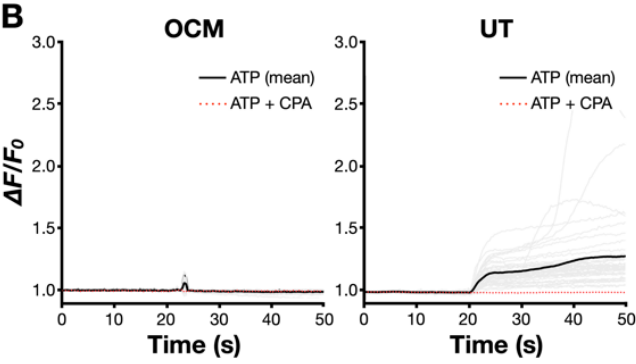

APV
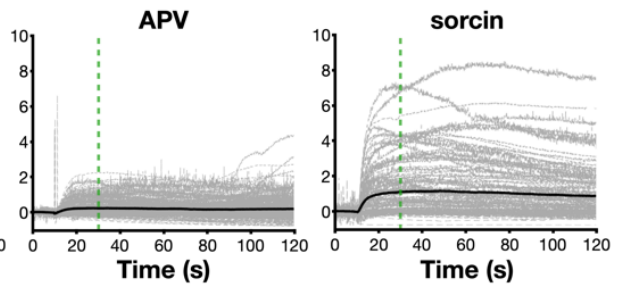

E

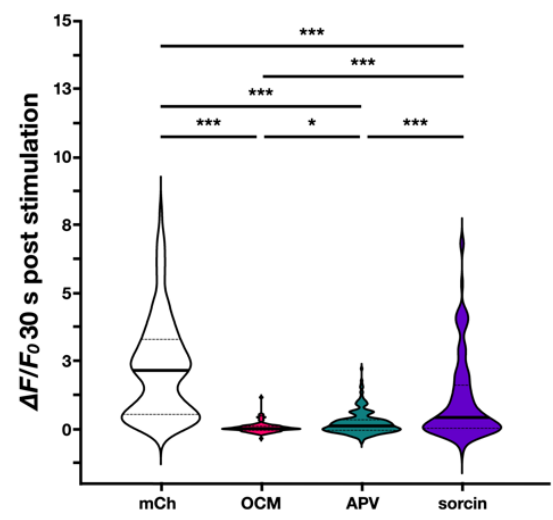

Figure 6. OCM influences calcium transient dynamics in transfected HEK293T cells. HEK293T cells were transiently transfected with fluorescently tagged CaBPs. A) Ocm mRNA is not endogenously detected in HEK293T cells. G3PDH and $\mathrm{Ocm}$ cDNA generated via RT-PCR from cell lysates of transfected $(\mathrm{Ocm}$ CFP) and untransfected HEK293T cells. Wells labeled "“_" are no transcript controls. B) HEK293T cells expressing fluorescently tagged OCM or control (untransfected) were incubated with Fluo-4 and stimulated with ATP. Changes in fluorescence of single cells are shown in grey. The solid black line indicates mean $\Delta F / F_{0}$ for that group. Dotted red lines represent control experiments including CPA, a SERCA inhibitor. C) Representative plots of $\Delta F / F_{o}$ upon stimulation with ionomycin. Changes in fluorescence of single cells are shown in grey. Solid black line indicates mean $\Delta F / F_{0}$ for that group. Dashed green line marks $30 \mathrm{~s}$ post stimulation. D) Fluorescent proteins (red): mCh-only, Ocm-mCh, Apv-mCh (not shown), Sri-mCh (not shown) were incubated with Fluo-4 (green) and stimulated with ionomycin. Shown are still images before $(0 \mathrm{~s})$ and $30 \mathrm{~s}$ post-stimulation with ionomycin. Scale bar $=50 \mu \mathrm{m}$. E) Violin plots of $\Delta F / F_{0} 30$ seconds post stimulation with ionomycin for HEK293T cells positive for: $\mathrm{mCh}$ (white), OCM (pink), APV (teal), and sorcin (purple). Solid lines represent medians. Dashed lines represent quartiles. $n \geq 100$ cells per group. 


\section{Supplemental Figure Legends}

Figure S01. Plasmid and Gene Sequences. Rat Ocm, Apv, Sri nucleotide sequences, pOcmCFP, $\mathrm{pOcm}$-mCh, $\mathrm{p} A p v$-mCh, $\mathrm{p} S r i$-mCh, pmCh plasmid nucleotide sequences and plasmid maps.

Figure S02. CFP and Fluo-4 excitation filters for $\mathrm{Ca}^{2+}$ transients in mammalian cells. Excitation (dotted lines, no fill) and emission (color filled) plots are shown for both fluorophores. Filters are shown as highlighted rectangles. Visual created using Fluorescence SpectraViewer (ThermoFisher).

Figure S03. Primer Sequences. Table of primer sequences used for qRT-PCR and PCR. Text Figure.

Figure S04. qRT-PCR Data and Calculations. Spreadsheets containing raw Cq values, 2$(\Delta \Delta \mathrm{Cq})$ values, and calculations for all qRT-PCR experiments.

Figure S05. P0 $\mathrm{Ocm}^{+/-}$local $\mathrm{KCl}$ application Calcium Transient. Video (.avi) file of Fluo-4 incubated $\mathrm{P} 0 \mathrm{Ocm}^{+/-}$spiral stimulated with $\mathrm{KCl} .19 .70 \mathrm{~s}$.

Figure S06. P0 $\mathrm{Ocm}^{-/}$local $\mathrm{KCl}$ application Calcium Transient. Video (.avi) file of Fluo-4 incubated P0 $\mathrm{Ocm}^{-/-}$spiral stimulated with $\mathrm{KCl} .19 .70 \mathrm{~s}$.

Figure S07. P3 $\mathrm{Ocm}^{+/}$local $\mathrm{KCl}$ application Calcium Transient. Video (.avi) file of Fluo-4 incubated P3 $\mathrm{Ocm}^{+/-}$spiral stimulated with $\mathrm{KCl} .06 .50 \mathrm{~s}$.

Figure S08. P3 $\mathrm{Ocm}^{-/}$local $\mathrm{KCl}$ application Calcium Transient. Video (.avi) file of Fluo-4 incubated P3 $\mathrm{Ocm}^{-/-}$spiral stimulated with $\mathrm{KCl} .06 .50 \mathrm{~s}$.

Figure S09. DPOAE threshold measurements (dB SPL) of 1 month-old C57B1/6 $\mathrm{Ocm}^{+/+} ; \mathrm{Apv}^{+/+}(\mathrm{n}=7$, black squares $), \mathrm{Ocm}^{-/} ; \mathrm{Apv}^{+/+}\left(\mathrm{n}=9\right.$, red filled circles) and $\mathrm{Ocm}^{-/} ; \mathrm{Apv}^{-/-}$ $(\mathrm{n}=10$, red outlined circles) $\mathrm{C} 57 \mathrm{Bl} / 6$ mice. Mean and SEM are plotted. **significant difference at $32 \mathrm{kHz}$ between $\mathrm{Ocm}^{+/+} ; \mathrm{Apv}^{+/+}$and $\mathrm{Ocm}^{-/-} ; \mathrm{Apv}^{+/+}(p=0.0021$, Tukey's multiple comparisons).

Figure S10. P3 $\mathrm{Ocm}^{+/} ; \mathrm{Apv}^{+/+} \mathrm{KCl}$ superfusion Calcium Transient. Video file (.avi) of Fluo-4 incubated dissected organ of Corti spiral stimulated via $\mathrm{KCl}$ superfusion. $233.33 \mathrm{~s}$.

Figure S11. P3 $\mathrm{Ocm}^{+/-} ; \mathrm{Apv}^{-/-} \mathrm{KCl}$ superfusion Calcium Transient. Video file (.avi) of Fluo-4 incubated dissected organ of Corti spiral stimulated via $\mathrm{KCl}$ superfusion. $200.00 \mathrm{~s}$.

Figure S12. P3 $\mathrm{Ocm}^{-/} ; \mathrm{Apv}^{-/-} \mathrm{KCl}$ superfusion Calcium Transient. Video file (.avi) of Fluo-4 incubated dissected organ of Corti spiral stimulated via $\mathrm{KCl}$ superfusion. $200.00 \mathrm{~s}$.

Figure S13. Fura-2 Calibration Curve. 


\section{References}

[1] M. Beurg, R. Fettiplace, J.-H. Nam, and A. J. Ricci, "Localization of inner hair cell mechanotransducer channels using high-speed calcium imaging," Nature neuroscience, vol. 12, no. 5, pp. 553-558, 2009, doi: https://doi.org/10.1038/nn.2295.

[2] M. Beurg, M. G. Evans, C. M. Hackney, and R. Fettiplace, "A large-conductance calciumselective mechanotransducer channel in mammalian cochlear hair cells," Journal of Neuroscience, vol. 26, no. 43, pp. 10992-11000, 2006, doi: https://doi.org/10.1523/JNEUROSCI.2188-06.2006.

[3] M. G. Layton, D. Robertson, A. W. Everett, W. H. Mulders, and G. K. Yates, "Cellular localization of voltage-gated calcium channels and synaptic vesicle-associated proteins in the guinea pig cochlea," Journal of molecular neuroscience, vol. 27, no. 2, pp. 225-244, 2005, doi: https://doi.org/10.1385/JMN:27:2:225.

[4] E. N. Yamoah, E. A. Lumpkin, R. A. Dumont, P. J. Smith, A. Hudspeth, and P. G. Gillespie, "Plasma membrane $\mathrm{Ca}^{2+}$-ATPase extrudes $\mathrm{Ca}^{2+}$ from hair cell stereocilia," Journal of Neuroscience, vol. 18, no. 2, pp. 610-624, 1998, doi: https://doi.org/10.1523/JNEUROSCI.18-02-00610.1998.

[5] Q. Chen, S. Mahendrasingam, J. A. Tickle, C. M. Hackney, D. N. Furness, and R. Fettiplace, "The development, distribution and density of the plasma membrane calcium ATPase 2 calcium pump in rat cochlear hair cells," Eur J Neurosci, vol. 36, no. 3, pp. 2302-10, Aug 2012, doi: https://doi.org/10.1111/j.1460-9568.2012.08159.x.

[6] M. Patterson, J. Sneyd, and D. D. Friel, "Depolarization-induced calcium responses in sympathetic neurons: relative contributions from $\mathrm{Ca}^{2+}$ entry, extrusion, $\mathrm{ER} /$ mitochondrial $\mathrm{Ca}^{2+}$ uptake and release, and $\mathrm{Ca}^{2+}$ buffering," (in eng), J Gen Physiol, vol. 129, no. 1, pp. 29-56, Jan 2007, doi: https://doi.org/10.1085/igp.200609660.

[7] M. Beurg, J.-H. Nam, Q. Chen, and R. Fettiplace, "Calcium balance and mechanotransduction in rat cochlear hair cells," Journal of neurophysiology, vol. 104, no. 1, pp. 18-34, 2010, doi: https://doi.org/10.1152/jn.00019.2010.

[8] R. Fettiplace and J.-H. Nam, "Tonotopy in calcium homeostasis and vulnerability of cochlear hair cells," Hearing research, vol. 376, pp. 11-21, 2019, doi: https://doi.org/10.1016/j.heares.2018.11.002.

[9] T. Yang, E. S. Scholl, N. Pan, B. Fritzsch, F. Haeseleer, and A. Lee, "Expression and Localization of CaBP Ca2+ Binding Proteins in the Mouse Cochlea," (in eng), PLoS One, vol. 11, no. 1, p. e0147495, 2016, doi: https://doi.org/10.1371/journal.pone.0147495.

[10] L. K. Climer et al., "Oncomodulin Delays Age-Related Hearing Loss in C57 and CBA Mice," bioRxiv, p. 2021.06.11.448116, 2021, doi: https://doi.org/10.1101/2021.06.11.448116.

[11] W. P. Yang, D. Henderson, B. H. Hu, and T. M. Nicotera, "Quantitative analysis of apoptotic and necrotic outer hair cells after exposure to different levels of continuous noise," Hearing research, vol. 196, no. 1-2, pp. 69-76, 2004, doi:

https://doi.org/10.1016/j.heares.2004.04.015

[12] C. M. Hackney, S. Mahendrasingam, A. Penn, and R. Fettiplace, "The Concentrations of Calcium Buffering Proteins in Mammalian Cochlear Hair Cells," (in en), Journal of Neuroscience, vol. 25, no. 34, pp. 7867-7875, 2005/08/24/ 2005, doi: https://doi.org/10.1523/JNEUROSCI.1196-05.2005. 
[13] A. K. Pak and N. B. Slepecky, "Cytoskeletal and calcium-binding proteins in the mammalian organ of Corti: cell type-specific proteins displaying longitudinal and radial gradients," (in en), Hearing Research, vol. 91, no. 1-2, pp. 119-135, 1995/11// 1995, doi: https://10.1016/0378-5955(95)00173-5.

[14] D. D. Simmons, B. Tong, A. D. Schrader, and A. J. Hornak, "Oncomodulin identifies different hair cell types in the mammalian inner ear," (in en), Journal of Comparative Neurology, vol. 518, no. 18, pp. 3785-3802, 2010 2010, doi: https://doi.org/10.1002/cne.22424.

[15] D. Yang, I. Thalmann, R. Thalmann, and D. Simmons, "Expression of $\alpha$ and $\beta$ parvalbumin is differentially regulated in the rat organ of corti during development," Journal of neurobiology, vol. 58, no. 4, pp. 479-492, 2004, doi: https://doi.org/10.1002/neu.10289.

[16] Y. Li, H. Liu, K. P. Giffen, L. Chen, K. W. Beisel, and D. Z. Z. He, "Transcriptomes of cochlear inner and outer hair cells from adult mice," Scientific Data, vol. 5, no. 1, p. 180199, 2018/10/02 2018, doi: https://doi.org/10.1038/sdata.2018.199.

[17] P. T. Ranum et al., "Insights into the Biology of Hearing and Deafness Revealed by SingleCell RNA Sequencing," (in en), Cell Reports, vol. 26, no. 11, pp. 3160-3171.e3, 2019/03// 2019, doi: https://doi.org/10.1016/i.celrep.2019.02.053.

[18] B. Tong, A. J. Hornak, S. F. Maison, K. K. Ohlemiller, M. C. Liberman, and D. D. Simmons, "Oncomodulin, an EF-Hand $\mathrm{Ca}^{2+}$ Buffer, Is Critical for Maintaining Cochlear Function in Mice," The Journal of Neuroscience, vol. 36, no. 5, pp. 1631-1635, 2016, doi: https://doi.org/10.1523/jneurosci.3311-15.2016.

[19] L. Airaksinen, J. Virkkala, A. Aarnisalo, M. Meyer, J. Ylikoski, and M. S. Airaksinen, "Lack of Calbindin-D28k Does Not Affect Hearing Level or Survival of Hair Cells in Acoustic Trauma," ORL, vol. 62, no. 1, pp. 9-12, 2000, doi: https://doi.org/10.1159/000027708.

[20] T. Pangršič et al., "EF-hand protein Ca2+ buffers regulate Ca2+ influx and exocytosis in sensory hair cells," Proceedings of the National Academy of Sciences, vol. 112, no. 9, pp. E1028-E1037, 2015, doi: https://doi.org/10.1073/pnas.1416424112.

[21] L. K. Climer, A. M. Cox, T. J. Reynolds, and D. D. Simmons, "Oncomodulin: the enigmatic parvalbumin protein," Frontiers in molecular neuroscience, vol. 12, p. 235, 2019, doi: https://doi.org/10.3389/fnmol.2019.00235.

[22] W. Marcotti and C. J. Kros, "Developmental expression of the potassium current IK,n contributes to maturation of mouse outer hair cells," (in eng), The Journal of physiology, vol. 520 Pt 3, no. Pt 3, pp. 653-660, 1999, doi: https://doi.org/10.1111/j.1469-

7793.1999.00653.x.

[23] J.-Y. Jeng et al., "Biophysical and morphological changes in inner hair cells and their efferent innervation in the ageing mouse cochlea," The Journal of Physiology, vol. 599, no. 1, pp. 269-287, 2021, doi: https://doi.org/10.1113/JP280256.

[24] J. Y. Jeng et al., "Age-related changes in the biophysical and morphological characteristics of mouse cochlear outer hair cells," The Journal of Physiology, vol. 598, no. 18, pp. 3891-3910, 2020, doi: https://doi.org/10.1113/JP279795.

[25] F. Ceriani et al., "Coordinated calcium signalling in cochlear sensory and non-sensory cells refines afferent innervation of outer hair cells," The EMBO journal, vol. 38, no. 9, 2019, doi: https://doi.org/10.15252/embj.201899839. 
[26] F. Ceriani and F. Mammano, "Calcium signaling in the cochlea-Molecular mechanisms and physiopathological implications," Cell Communication and Signaling, vol. 10, no. 1, pp. 1-12, 2012, doi: https://doi.org/10.1186/1478-811X-10-20.

[27] L. F. Corns et al., "Mechanotransduction is required for establishing and maintaining mature inner hair cells and regulating efferent innervation," Nature Communications, vol. 9, no. 1, p. 4015, 2018/10/01 2018, doi: https://doi.org/10.1038/s41467-01806307-w.

[28] M. Müller, K. v. Hünerbein, S. Hoidis, and J. W. T. Smolders, "A physiological placefrequency map of the cochlea in the CBA/J mouse," Hearing Research, vol. 202, no. 1, pp. 63-73, 2005/04/01/2005, doi: https://doi.org/10.1016/j.heares.2004.08.011.

[29] P. Wangemann and J. Schacht, "Homeostatic Mechanisms in the Cochlea," in The Cochlea, P. Dallos, A. N. Popper, and R. R. Fay Eds. New York, NY: Springer New York, 1996, pp. 130-185.

[30] J. Schindelin et al., "Fiji: an open-source platform for biological-image analysis," Nature methods, vol. 9, no. 7, pp. 676-682, 2012, doi: https://doi.org/10.1038/nmeth.2019.

[31] F. Aulestia et al., "Two distinct calcium pools in the endoplasmic reticulum of HEK-293T cells," The Biochemical journal, vol. 435, pp. 227-35, 04/01 2011, doi: https://doi.org/10.1042/BJ20101427.

[32] P. Melgar-Rojas, J. C. Alvarado, V. Fuentes-Santamaría, M. C. Gabaldón-UII, and J. M. Juiz, "Validation of Reference Genes for RT-qPCR Analysis in Noise-Induced Hearing Loss: A Study in Wistar Rat," (in eng), PloS one, vol. 10, no. 9, pp. e0138027-e0138027, 2015, doi: https://doi.org/10.1371/journal.pone.0138027.

[33] T. D. Schmittgen and K. J. Livak, "Analyzing real-time PCR data by the comparative CT method," Nature Protocols, vol. 3, no. 6, pp. 1101-1108, 2008/06/01 2008, doi: https://doi.org/10.1038/nprot.2008.73.

[34] D. Pauli-Magnus, G. Hoch, N. Strenzke, S. Anderson, T. Jentsch, and T. Moser, "Detection and differentiation of sensorineural hearing loss in mice using auditory steady-state responses and transient auditory brainstem responses," Neuroscience, vol. 149, no. 3, pp. 673-684, 2007, doi: https://doi.org/10.1016/j.neuroscience.2007.08.010.

[35] R. Jain et al., "Cochlear proteins associated with noise-induced hearing loss: An update," (in English), Indian Journal of Occupational and Environmental Medicine, 2018/05/01/ 2018, doi: https://doi.org/10.4103/ijoem.IJOEM 43_18.

[36] S. F. Maison, X.-P. Liu, R. A. Eatock, D. R. Sibley, D. K. Grandy, and M. C. Liberman, "Dopaminergic signaling in the cochlea: receptor expression patterns and deletion phenotypes," Journal of Neuroscience, vol. 32, no. 1, pp. 344-355, 2012, doi: https://doi.org/10.1523/JNEUROSCl.4720-11.2012.

[37] J. Y. Jeng et al., "Hair cell maturation is differentially regulated along the tonotopic axis of the mammalian cochlea," The Journal of physiology, vol. 598, no. 1, pp. 151-170, 2020, doi: https://doi.org/10.1113/JP279012.

[38] W. Zheng, Y. Xie, G. Li, J. Kong, J. Q. Feng, and Y. C. Li, "Critical role of calbindin-D28k in calcium homeostasis revealed by mice lacking both vitamin $D$ receptor and calbindinD28k," Journal of Biological Chemistry, vol. 279, no. 50, pp. 52406-52413, 2004, doi: https://doi.org/10.1074/jbc.M405562200. 
[39] B. Csillik, B. Schwaller, A. Mihaly, T. Henzi, E. Losonczi, and E. Knyihar-Csillik, "Upregulated expression of oncomodulin, the beta isoform of parvalbumin, in perikarya and axons in the diencephalon of parvalbumin knockout mice," Neuroscience, vol. 165, no. 3, pp. 749-757, 2010/02/03/ 2010, doi: https://doi.org/10.1016/j.neuroscience.2009.10.048.

[40] T. H. Koo, H. Yang, B. S. An, K. C. Choi, S. H. Hyun, and E. B. Jeung, "Calcium transport genes are differently regulated in maternal and fetal placenta in the knockout mice of calbindin-D9k and-D28k," Molecular reproduction and development, vol. 79, no. 5, pp. 346-355, 2012, doi: https://doi.org/10.1002/mrd.22033.

[41] Z. Song, S. Vijayaraghavan, and C. D. Sladek, "ATP increases intracellular calcium in supraoptic neurons by activation of both P2X and P2Y purinergic receptors," American Journal of Physiology-Regulatory, Integrative and Comparative Physiology, vol. 292, no. 1, pp. R423-R431, 2007, doi: https://doi.org/10.1152/ajpregu.00495.2006

[42] W. Fischer, H. Franke, H. Gröger-Arndt, and P. Illes, "Evidence for the existence of P2Y 1, 2, 4 receptor subtypes in HEK-293 cells: reactivation of P2Y 1 receptors after repetitive agonist application," Naunyn-Schmiedeberg's archives of pharmacology, vol. 371, no. 6, pp. 466-472, 2005, doi: https://doi.org/10.1007/s00210-005-1070-6.

[43] M. Hoth and R. Penner, "Depletion of intracellular calcium stores activates a calcium current in mast cells," Nature, vol. 355, no. 6358, pp. 353-356, 1992/01/01 1992, doi: https://doi.org/10.1038/355353a0.

[44] A. J. Morgan and R. Jacob, "Ionomycin enhances $\mathrm{Ca}^{2+}$ influx by stimulating storeregulated cation entry and not by a direct action at the plasma membrane," Biochemical Journal, vol. 300, no. 3, pp. 665-672, 1994, doi: https://doi.org/10.1042/bj3000665.

[45] L. Kolla et al., "Characterization of the development of the mouse cochlear epithelium at the single cell level," (in eng), Nat Commun, vol. 11, no. 1, p. 2389, May 13 2020, doi: https://doi.org/10.1038/s41467-020-16113-y.

[46] D. I. Scheffer, J. Shen, D. P. Corey, and Z. Y. Chen, "Gene Expression by Mouse Inner Ear Hair Cells during Development," (in en), Journal of Neuroscience, vol. 35, no. 16, pp. 6366-6380, 2015/04/22/ 2015, doi: https://doi.org/10.1523/JNEUROSCI.5126-14.2015.

[47] Q. Cai et al., "Molecular profile of cochlear immunity in the resident cells of the organ of Corti," Journal of Neuroinflammation, vol. 11, 2014/10/14/ 2014, doi: https://doi.org/10.1523/JNEUROSCI.5083-14.2015.

[48] R. Elkon et al., "RFX transcription factors are essential for hearing in mice," Nature Communications, vol. 6 , no. 1 , p. $8549,2015 / 10 / 15$ 2015, doi: https://doi.org/10.1038/ncomms9549.

[49] J. Orvis et al., "gEAR: Gene Expression Analysis Resource portal for community-driven, multi-omic data exploration," Nature Methods, 2021/06/25 2021, doi: https://doi.org/10.1038/s41592-021-01200-9.

[50] I. Genovese et al., "Sorcin is an early marker of neurodegeneration, $\mathrm{Ca}(2+)$ dysregulation and endoplasmic reticulum stress associated to neurodegenerative diseases," Cell Death Dis, vol. 11, no. 10, p. 861, Oct 15 2020, doi: 10.1038/s41419-020-03063-y.

[51] B. Schwaller, "Cytosolic Ca ${ }^{2+}$ buffers," Cold Spring Harbor perspectives in biology, vol. 2, no. 11, p. a004051, 2010, doi: https://doi.org/10.1101/cshperspect.a035543. 
[52] M. W. Berchtold, "Structure and expression of genes encoding the three-domain Ca2+binding proteins parvalbumin and oncomodulin," (in en), Biochimica et Biophysica Acta (BBA) - Gene Structure and Expression, vol. 1009, no. 3, pp. 201-215, 1989/12// 1989, doi: https://doi.org/10.1016/0167-4781(89)90104-8.

[53] J. A. Cox, M. Milos, and J. P. MacManus, "Calcium- and magnesium-binding properties of oncomodulin. Direct binding studies and microcalorimetry," (in eng), J Biol Chem, vol. 265, no. 12, pp. 6633-7, Apr 25 1990, doi: https://doi.org/10.1016/S00219258(19)39196-3.

[54] M. T. Henzl and J. J. Tanner, "Solution structure of $\mathrm{Ca}^{2+}$-free rat beta-parvalbumin (oncomodulin)," (in eng), Protein science : a publication of the Protein Society, vol. 16, no. 9, pp. 1914-1926, 2007, doi: https://doi.org/10.1110/ps.072837307.

[55] L. Erb and G. A. Weisman, "Coupling of P2Y receptors to G proteins and other signaling pathways," (in eng), Wiley interdisciplinary reviews. Membrane transport and signaling, vol. 1, no. 6, pp. 789-803, Nov-Dec 2012, doi: https://doi.org/10.1002/wmts.62.

[56] G. Kasuya et al., "Structural insights into the competitive inhibition of the ATP-gated P2X receptor channel," Nature Communications, vol. 8, no. 1, p. 876, 2017/10/12 2017, doi: https://doi.org/10.1038/s41467-017-00887-9.

[57] J. B. Schachter, S. M. Sromek, R. A. Nicholas, and T. K. Harden, "HEK293 human embryonic kidney cells endogenously express the P2Y1 and P2Y2 receptors," Neuropharmacology, vol. 36, no. 9, pp. 1181-1187, 1997/09/01/ 1997, doi: https://doi.org/10.1016/S0028-3908(97)00138-X.

[58] R. A. Worthington, J. L. Dutton, P. Poronnik, M. R. Bennett, and J. A. Barden, "Localisation of $\mathrm{P} 2 \mathrm{X}$ receptors in human salivary gland epithelial cells and human embryonic kidney cells by sodium dodecyl sulfate-polyacrylamide gel electrophoresis/Western blotting and immunofluorescence," ELECTROPHORESIS: An International Journal, vol. 20, no. 10, pp. 2065-2070, 1999, doi: https://doi.org/10.1002/(SICI)1522-2683(19990701)20:10<2065::AIDELPS2065>3.0.CO;2-E.

[59] R. A. Worthington et al., "Point mutations confer loss of ATP-induced human P2X7 receptor function," FEBS Letters, vol. 512, no. 1, pp. 43-46, 2002/02/13/ 2002, doi: https://doi.org/10.1016/S0014-5793(01)03311-7.

[60] B. S. Khakh, X. R. Bao, C. Labarca, and H. A. Lester, "Neuronal P2X transmitter-gated cation channels change their ion selectivity in seconds," Nature Neuroscience, vol. 2, no. 4, pp. 322-330, 1999/04/01 1999, doi: https://doi.org/10.1038/7233. 